CARLOS NOBRE RABELO JÚNIOR

\title{
Avaliação da função gonadal em pacientes do sexo masculino com síndrome antifosfolípide
}

Tese apresentada à Faculdade de Medicina da Universidade de São Paulo para obtenção do título de Doutor em Ciências

Programa de Ciências Médicas Área de concentração: Processos Inflamatórios e Alérgicos

Orientador: Prof. Dr. Clovis Artur Almeida da Silva

São Paulo 
Dados Internacionais de Catalogação na Publicação (CIP)

Preparada pela Biblioteca da

Faculdade de Medicina da Universidade de São Paulo

Creprodução autorizada pelo autor

Rabelo-Júnior, Carlos Nobre

Avaliação da função gonadal em pacientes do sexo masculino com síndrome antifosfolípide/ Carlos Nobre Rabelo Júnior. -- São Paulo, 2011.

Tese(doutorado)--Faculdade de Medicina da Universidade de São Paulo.

Programa de Ciências Médicas. Área de concentração: Processos Inflamatórios e Alérgicos.

Orientador: Clovis Artur Almeida da Silva.

Descritores: 1.Síndrome antifofolípide 2.Masculino 3.Sêmen 4.Lúpus eritematoso sistêmico 5.Fertilidade 6.Anticorpos antiespermatozóides

USP/FM/DBD-266/11 
DEDICATÓRIA 
Aos meus pais, Carlos e Conceição, pela alegria $e$ simplicidade com que encaram a vida e por todo amor e dedicação com que criaram seus filhos ao longo dos anos. Aos meus irmãos, Sandra, Kátia e Charles, e aos meus adorados sobrinhos que, cada um ao seu modo, conseguem tornar minha vida e de meus pais repleta de felicidades. 
À Disciplina de Reumatologia da Faculdade de Medicina da Universidade de São Paulo por todo 0 apoio oferecido na elaboração desta tese, acolhendo-me de uma maneira exemplar e ajudando-me realização de uma importante conquista profissional. 


\section{AGRADECIMENTOS}

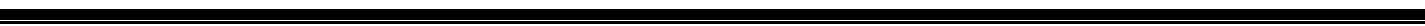


À Prof. aㅡoísa Bonfá, que mesmo sem o completo conhecimento de minha pessoa, conseguiu depositar a confiança que eu precisava para seguir em frente e concluir minha tese. São atitudes como essa que fazem a diferença na vida de um indivíduo. Meu eterno obrigado.

Ao Prof. Jozélio Freire, que com sua simplicidade e força de vontade, mostrou-me que todas as coisas boas que ouvira falar a seu respeito eram verdadeiras, além do exímio cuidado com os seus pacientes.

A todos os funcionários do Centro de Dispensação de Medicações de Alto Custo (CDMAC), que viabilizaram a maioria das etapas de meu estudo, sempre disponíveis e atenciosos.

Às minhas amigas do Laboratório de Reprodução Humana, Maribê, Rosa e Camila. Queria que vocês soubessem que são pessoas iluminadas e que o que fizeram por mim não tem preço e nem nome.

Aos médicos Dr. Osmar Saito e Dr. Marcelo Coccuza, que com sua paciência e determinação, conseguiram ser mais que colaboradores em minha tese. Seus simples gestos de ajuda, por mais que não tenham percebido, fizeram-me ter coragem de enfrentar essa longa jornada.

Aos funcionários do Laboratório de Investigação Médica (LIM) da Reumatologia, pelo apoio incondicional na obtenção de meus objetivos.

Às secretárias da Reumatologia e da Pós-graduação, que me mostraram os caminhos nos momentos complicados com toda paciência e carinho. 
Aos amigos, Modesto, Daniel e Alberto, que me acolheram em minhas inúmeras idas e vindas durante esses anos e que souberam me incentivar quando mais precisei.

Aos meus melhores amigos, Amaurício e Deborah, que me apoiaram em todos os momentos de minha vida, principalmente nos mais difíceis, estando ao meu lado incondicionalmente.

Às minhas eternas "chefinhas", e por que não dizer "mães" da Reumatologia Pediátrica, Lúcia, Adriana e Bernadete, às quais devo minha eterna gratidão, não por serem as pessoas extraordinárias que todos conhecem, mas por deixar que isso consiga aliar-se à sua incontestável sabedoria para tornar seus "filhos" pessoas capazes de fazer o correto sempre.

Às minhas irmãs da Reumatologia Pediátrica, Adriana, Nádia, Kátia, Aline e Renata. Nossas longas conversas durante os anos de estudo até hoje estão em minha memória. Vocês tornaram a estadia longe da minha família algo tão especial que por vezes me sentia em casa quando estava com vocês. Obrigado.

Por último, ao meu grande mestre, pai e amigo Prof. Clovis, por tudo o que me ensinou e ainda vem ensinando em todos os aspectos de minha vida. Impressionante a forma como ele sabia, mesmo sem eu saber, o que era melhor para mim e para todos os que estão ao seu redor. A maneira como acolhe e confia nas pessoas, como incentiva e retribui o que the é dado, são características de um ser humano formidável. Saiba que carrego comigo todos os ensinamentos, "puxões de orelha" e algumas de suas 
características pessoais e que às vezes percebo estar agindo da mesma forma que você. Tenho orgulho da pessoa que você é e da pessoa que ajudou a me tornar. Muito obrigado por tudo. 
Este estudo foi financiado pela Fundação de Amparo à Pesquisa do Estado de São Paulo - FAPESP (2004/07832-2 e 2005/56482-7 concede ao CAS) e Conselho Nacional de Desenvolvimento Científico e Tecnológico - CNPQ (subvenções 3300665/2009-1 a JFC, 301411/2009-3 para EB e 300248/2008-3 para CAS) e Subsídios da Federico Fundação para JFC, EB e CAS. 


\section{NORMALIZAÇÃO ADOTADA}

Esta tese foi escrita de acordo com as novas regras ortográficas da língua portuguesa, válidas desde janeiro de 2009, e está de acordo com as seguintes normas em vigor no momento desta publicação:

Referências: adaptado de International Committee of Medical Journals Editors (Vancouver).

Universidade de São Paulo. Faculdade de Medicina. Divisão de Biblioteca e Documentação. Guia de apresentação de dissertações, teses e monografias. Elaborado por Anneliese Carneiro da Cunha, Maria Julia de A. L. Freddi, Maria F. Crestana, Marinalva de Souza Aragão, Suely Campos Cardoso, Valéria Vilhena. 3a․ ed. São Paulo: Divisão de Biblioteca e Documentação; 2011.

Abreviaturas dos títulos dos periódicos de acordo com "List of Journals Indexed in Index Medicus". 


\section{SUMÁRIO}

Lista de abreviaturas e siglas

Lista de tabelas

Resumo

Abstract

1 INTRODUÇÃO

2 OBJETIVOS 3

3 MÉTODOS 5

$\begin{array}{lll}\text { 3.1 Pacientes com SAF e controles } & 6\end{array}$

$\begin{array}{lll}3.2 & \text { Desenho e população do estudo }\end{array}$

$\begin{array}{lll}3.3 & \text { Aprovação por comissão de ética } & 7\end{array}$

$\begin{array}{lll}3.4 & \text { Dados demográficos e índice de massa corpórea } & 7\end{array}$

$\begin{array}{lll}3.5 & \text { Avaliação urológica } & 7\end{array}$

3.6 Ultrassonografia testicular com Doppler 8

3.7 Avaliação hormonal 8

3.8 Avaliação do sêmen 8

3.9 Avaliação clínica e tratamento 9

$\begin{array}{ll}3.10 & \text { Análise imunológica. } \\ \end{array}$

$\begin{array}{ll}3.11 & \text { Análise estatística } \\ \end{array}$

4 RESULTADOS 12

$\begin{array}{lll}4.1 & \text { Pacientes SAFP versus controles. } & 13\end{array}$

$\begin{array}{lll}4.2 & \text { Pacientes SAFP } & 16\end{array}$ 
4.3 Pacientes SAF-LES versus controles

$\begin{array}{lll}4.4 & \text { Pacientes SAF-LES } & 19\end{array}$

4.5 Pacientes SAFP versus SAF-LES 23

5 DISCUSSÃO 24

6 CONCLUSÕES 29

$\begin{array}{lll}7 & \text { REFERÊNCIAS } & 31\end{array}$

$\begin{array}{ll}\text { APÊNDICES } & 39\end{array}$

APÊNDICE 1 Artigo "Primary antiphospholipid syndrome: Morphofunctional penile abnormalities with normal sperm analysis"

APÊNDICE 2 Artigo "Moderate/severe erectile dysfunction in patients with antiphospholipid syndrome"

APÊNDICE 3 Artigo "Morphofunctional penile alterations with severe sperm abnormalities in antiphospholipid syndrome associated with systemic lupus erythematosus" 


\section{LISTA DE ABREVIATURAS E SIGLAS}

\begin{tabular}{|c|c|}
\hline Apl & Anticorpos antifosfolípides \\
\hline CFEV & Ciclofosfamida endovenosa \\
\hline DP & Desvio padrão \\
\hline FMUSP & Faculdade de Medicina da Universidade de São Paulo \\
\hline $\mathrm{FSH}$ & Hormônio foliculoestimulante \\
\hline LH & Hormônio luteinizante \\
\hline $\lg$ & Imunoglobulina \\
\hline IMC & Índice de massa corpórea \\
\hline LES & Lúpus eritematoso sistêmico \\
\hline OMS & Organização Mundial de Saúde \\
\hline SAF & Síndrome antifosfolípide \\
\hline SAFP & Síndrome antifosfolípide primária \\
\hline SAF-LES & $\begin{array}{l}\text { Síndrome antifosfolípide associada ao lúpus eritematoso } \\
\text { sistêmico }\end{array}$ \\
\hline SLEDAI & $\begin{array}{l}\text { Do inglês "Systemic Lupus Erythematosus Disease Activity } \\
\text { Index" }\end{array}$ \\
\hline SLICC/ACR-DI & $\begin{array}{l}\text { Do inglês "Systemic Lupus International Collaborating } \\
\text { Clinics/American College of Rheumatology Damage Index" }\end{array}$ \\
\hline TSH & Hormônio tireoestimulante \\
\hline
\end{tabular}




\section{LISTA DE TABELAS}

Tabela 1 Dados demográficos, índice de massa corpórea (IMC), antropometria do pênis e volume testicular por ultrassonografia em pacientes com síndrome antifosfolípide primária (SAFP), síndrome antifosfolípide associada ao lúpus eritematoso sistêmico (SAF-LES) e controles

Tabela 2 Análise do sêmen, anticorpos antiespermatozóide e avaliação hormonal em pacientes com síndrome antifosfolípide primária (SAFP), síndrome antifosfolípide associada ao lúpus eritematoso sistêmico (SAF-LES) e controles

Tabela 3 Dados demográficos, índice de massa corpórea (IMC), antropometria do pênis, volume testicular por ultrassonografia, análise do sêmen, anticorpos antiespermatozóide, avaliação hormonal e características clínicas e laboratoriais no início do estudo em pacientes com síndrome antifosfolípide primária (SAFP) com e sem eventos arteriais anteriores 
Tabela 4 Dados demográficos, índice de massa corpórea (IMC), antropometria do pênis, volume testicular por ultrassonografia, análise do sêmen, anticorpos antiespermatozóide, avaliação hormonal, características clínicas e laboratoriais no início do estudo, atividade e dano cumulativo da doença em pacientes com síndrome antifosfolípide associada ao lúpus eritematoso sistêmico (SAF-LES) com e sem eventos arteriais anteriores

Tabela 5 Dados demográficos, índice de massa corpórea (IMC), antropometria do pênis, volume testicular por ultrassonografia, análise do sêmen, anticorpos antiespermatozóide, avaliação hormonal, atividade e dano cumulativo da doença em pacientes com síndrome antifosfolípide associada ao lúpus eritematoso sistêmico (SAF-LES), tratados ou não com ciclofosfamida endovenosa (CFEV) 


\section{RESUMO}

Rabelo-Júnior CN. Avaliação da função gonadal em pacientes do sexo masculino com síndrome antifosfolípide [tese]. São Paulo: Faculdade de Medicina, Universidade de São Paulo; 2011.

INTRODUÇÃO. A síndrome antifiosfolípide (SAF) é uma condição trombofílica autoimune associada a títulos elevados e persistentes de anticorpos antifosfolípides. Caracteriza-se por tromboses em diversos órgãos, incluindo os testículos. OBJETIVO. Realizar uma avaliação global da função gonadal em pacientes masculinos com SAF primária (SAFP) e SAF associada ao lúpus eritematoso sistêmico (SAF-LES). MÉTODOS. Estudo transversal realizado em 22 pacientes (12 com SAFP e $10 \mathrm{com}$ SAF-LES) e 20 controles saudáveis pareados por sexo e idade. Os pacientes foram avaliados em relação a dados demográficos, exame urológico, ultrassonografia testicular, perfil hormonal, análise do sêmen, anticorpos antiespermatozóides e características clínicas e laboratoriais. RESULTADOS. A mediana da idade atual foi semelhante nos pacientes com SAFP e controles $(p=0,27)$, assim como naqueles com SAF-LES e controles $(p=0,31)$. Disfunção erétil foi significantemente maior nos pacientes com SAFP comparado aos controles ( $25 \%$ vs. $0 \%, p=0,044$ ), e nos SAF-LES comparado aos controles $(30 \%$ vs. $0 \%, p=0,029)$. Com relação à antropometria do pênis, a análise dos subgrupos de pacientes com $(n=7)$ e sem $(n=5)$ tromboses arteriais prévias demonstrou que a mediana da circunferência do pênis foi significantemente menor em SAFP com trombose arterial versus sem trombose arterial $[8,1(6-10)$ vs. $10,2(10-11) \mathrm{cm}$, 
$p=0,007]$, bem como também observado em pacientes com SAF-LES com $(n=2)$ e sem $(n=8)$ eventos arteriais prévios $[7,5(7-8)$ vs. $9,18(8-10,5) \mathrm{cm}$, $p=0,039]$. A mediana da circunferência do pênis foi significantemente menor nos pacientes com SAFP com disfunção erétil versus sem essa alteração [7,5 (6-9,5) vs. $9,5(7,5-11) \mathrm{cm}, \mathrm{p}=0,039]$, assim como no grupo de SAF-LES [8,17 (8-8,5) vs. $9,14(7-10,5) \mathrm{cm}, \mathrm{p}=0,0397]$. Com relação à avaliação da função testicular, todos os parâmetros foram semelhantes nos pacientes com SAFP e controles $(p>0,05)$. Por sua vez, as medianas de concentração e de mobilidade dos espermatozóides foram significantemente menores nos pacientes com SAF-LES comparado aos controles $[41,1$ (0-145) vs. 120,06 $(34,5-329) \times 10^{6} / \mathrm{mL}, p=0,003 ; 47,25(0-87,5)$ vs. $65,42 \quad(43-82) \%, p=0,047 ;$ respectivamente], assim como a frequência de oligo/azoopermia (40\% vs. $0 \%, p=0,007)$. A análise dos pacientes com SAF-LES mostrou que as medianas da concentração e da contagem total de espermatozóides foram significantemente menores nos que usaram ciclofosfamida endovenosa versus os que não usaram tal medicação $[6,87(0-23,5)$ vs. $63,9 \quad(7,5-145)$ x $10^{6} / \mathrm{mL}, \quad \mathrm{p}=0,04 ; 16,12(0-55,5)$ vs. $226,25(8,5-471) \times 10^{6}, \mathrm{p}=0,035 ;$ respectivamente]. CONCLUSÕES. Diminuição do tamanho peniano nos pacientes com SAFP e SAF-LES com disfunção erétil associada foi evidenciada, além de disfunção testicular secundária ao uso de agentes alquilantes nos pacientes com SAF-LES.

DESCRITORES: Síndrome antifosfolípide, sexo masculino, sêmen, lúpus eritematoso sistêmico, fertilidade, anticorpos antiespermatozóides. 


\section{ABSTRACT}

\section{Rabelo-Júnior CN. Evaluation of gonadal function in male patients with}

antiphospholipid syndrome [thesis]. São Paulo: "Faculdade de Medicina, Universidade de São Paulo"; 2011.

INTRODUCTION. Antiphospholipid syndrome (APS) is an autoimmune thrombophilic condition associated with persistent high titers of antiphospholipid antibodies. It is characterized by thrombosis in various organs including the testes. OBJECTIVE. To perform a global testicular assessment in male primary antiphospholipid syndrome (PAPS) and secondary systemic lupus erythematosus-APS (SLE-APS) patients, and healthy controls. METHODS. A cross-sectional study was conducted in 22 APS (12 PAPS and 10 SLE-APS) male patients, and 20 healthy controls. They were assessed by demographic data, systematic urological examination, testicular ultrasound, hormone profile, sperm analysis, antisperm antibodies, clinical features and treatment. RESULTS. The median of current age was similar in PAPS patients and controls ( $p=0.27)$, likewise in SLE-APS and controls $(p=0.31)$. Erectile dysfunction was significantly higher in PAPS patients compared than controls $(25 \%$ vs. $0 \%, p=0.044)$, and in SLE-APS and controls $(30 \%$ vs. $0 \%, p=0.029)$. Regarding the penile anthropometry, the analysis of subgroups of PAPS patients with $(n=7)$ and without $(n=5)$ previous arterial thrombosis demonstrated that the median circumference penis was significantly lower in PAPS with arterial thrombosis versus without [8.1 (6-10) vs. $10.2(10-11) \mathrm{cm}, \mathrm{p}=0.007]$, as also observed in 
SLE-APS patients with $(n=2)$ and without $(n=8)$ previous arterial events [7.5 (7-8) vs. $9.18(8-10.5) \mathrm{cm}, \mathrm{p}=0.039]$. In addition, the median penis circumference was significantly lower in PAPS patients with erectile dysfunction versus without this alteration [7.5 (6-9.5) vs. $9.5(7.5-11) \mathrm{cm}$, $\mathrm{p}=0.039]$, likewise in SLE-APS patients [8.17 (8-8.5) vs. $9.14(7-10.5) \mathrm{cm}$, $\mathrm{p}=0.0397]$. Regarding gonadal evaluation, these parameters were uniformly normal in PAPS versus controls $(p>0.05)$. In contrast, the median of sperm concentration and sperm motility were significantly lower in SLE-APS patients compared to controls [41.1 (0-145) vs. $120.06(34.5-329) \times 10^{6} / \mathrm{mL}$, $p=0.003 ; 47.25$ (0-87.5) vs. $65.42(43-82) \%, p=0.047$; respectively], likewise the frequency of oligo/azoopermia ( $40 \%$ vs. $0 \%, p=0.007)$. The analysis of SLE-APS patients showed that the median of sperm concentration and total sperm count were significantly lower in SLE-APS patients treated with intravenous cyclophosphamide versus untreated $[6.87$ (0-23.5) vs. 63.9 $(7.5-145) \times 10^{6} / \mathrm{mL}, \mathrm{p}=0.04 ; 16.12(0-55.5)$ vs. $226.25(8.5-471) \times 10^{6}$, $\mathrm{p}=0.035$; respectively]. CONCLUSIONS. We have identified reduced penile size in PAPS and SLE-APS patients with deleterious erectile function, and testicular dysfunction due to alkylating agents in SLE-APS patients.

DESCRIPTORS: antiphospholipid syndrome, male, sperm, systemic lupus erythematosus, fertility, antisperm antibodies. 
1 INTRODUÇÃO

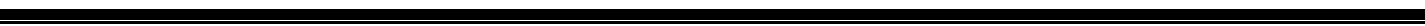


A síndrome antifosfolípide (SAF) é uma condição trombofílica autoimune caracterizada por tromboses venosas e/ou arteriais associadas ou não à morbidade gestacional, na presença de títulos elevados e persistentes de anticorpos antifosfolípides (aPL). ${ }^{1}$ Cerca de $8 \%$ a $18 \%$ dos pacientes afetados são do sexo masculino, podendo ser classificada em primária (SAFP) ou secundária a outras doenças, principalmente ao lúpus eritematoso sistêmico (SAF-LES), ${ }^{2,3}$ e pode acometer um grande número de órgãos e sistemas, incluindo os testículos. ${ }^{4}$

A avaliação testicular nas doenças reumatológicas autoimunes exige um exame urológico completo para detectar alterações no esperma devido à idade, ${ }^{5,6}$ anormalidades genitais, ${ }^{7}$ disfunção do eixo hipotálamo-hipofisário, anticorpos antiespermatozóides ${ }^{8}$ e efeitos do tratamento medicamentoso utilizado, especialmente os agentes imunossupressores. $^{9-15}$

Já foram relatadas anormalidades graves no esperma associadas à atrofia testicular e níveis elevados de hormônio foliculoestimulante $(\mathrm{FSH})^{11}$ em pacientes com LES tratados com ciclofosfamida endovenosa (CFEV) ${ }^{12,13}$ e redução das dimensões do pênis em pré-púberes com LES sem SAF e/ou disfunção erétil. ${ }^{16}$ Trombose testicular secundário à SAFP ou SAF-LES foi descrita em poucos casos na literatura. ${ }^{3,17-21}$ Porém, não existe até 0 presente momento nenhum estudo sistemático avaliando a função gonadal global, incluindo avaliações testicular e peniana, em pacientes com estas condições. 
2 OBJetivos 
1 Avaliar função gonadal em pacientes com SAFP e SAF-LES e controles sadios.

2 Verificar possíveis associações entre disfução gonadal em pacientes com SAFP e SAF-LES com: dados demográficos, índice de massa corpórea (IMC), exame urológico, disfunção erétil, análise do sêmen, perfil hormonal e achados clínicos e laboratoriais. 
3 MÉTODOS 


\subsection{Pacientes com SAF e controles}

Foram selecionados inicialmente 38 pacientes do sexo masculino com SAF. Dezesseis pacientes foram excluídos devido a: vasectomia (três pacientes), recusa em coletar as amostras do sêmem (nove pacientes) e associação com outras doenças reumáticas em quatro (poliarterite nodosa em dois, artrite reumatóide em um e espondilite anquilosante em um).

Nenhum dos sujeitos do estudo tinha hidrocele, hipospádia, criptorquidia, infecção testicular, câncer testicular, orquite, vasculite testicular, disfunção ureteral, história prévia de qualquer cirurgia testicular ou inguinal, diabetes mellitus, história prévia ou atual de uso de álcool e tabaco.

\subsection{Desenho e população do estudo}

Foi conduzido um estudo transversal em 22 pacientes do sexo masculino portadores de SAF (12 com SAFP e 10 com SAF-LES) acompanhados regularmente no Ambulatório de SAF da Divisão de Reumatologia do Hospital das Clínicas da Faculdade de Medicina da Universidade de SãoPaulo (FMUSP) no período de maio de 2008 a fevereiro de 2011. Todos os pacientes preencheram os critérios de Sapporo para o diagnóstico de $\mathrm{SAF}^{22} \mathrm{O}$ grupo controle incluiu 20 indivíduos saudáveis seguidos no Grupo Pré-vasectomia da Divisão de Urologia do Hospital Universitário da FMUSP. Todos os pacientes do estudo e controles estavam em estágio puberal de Tanner $5{ }^{23}$ 


\subsection{Aprovação por comissão de ética}

Este estudo foi aprovado pela Comissão de Ética para Análise de Projetos de Pesquisa do Hospital das Clínicas da FMUSP (CAPPesq). O termo de consentimento livre e esclarecido foi assinado por todos os participantes.

\subsection{Dados demográficos e índice de massa corpórea}

Foram registradas a idade atual, idade de espermarca (primeira ejaculação) e raça nos pacientes com SAF e controles, enquanto a idade no início da doença e duração da doença nos pacientes com SAF. O IMC foi definido pela fórmula: $I M C=$ peso (em quilogramas) dividido pela altura (em metros) ao quadrado.

\subsection{Avaliação urológica}

A avaliação clínica da genitália incluiu a análise dos testículos, epidídimos, canal deferente, bolsa escrotal e pênis. O comprimento do pênis foi medido como a distância linear ao longo do lado dorsal que se estende desde a junção da pele pubopeniana até a ponta da glande no estado flácido, enquanto que a circunferência do pênis foi medida no meio do seu maior eixo. ${ }^{24} \mathrm{~A}$ avaliação da disfunção erétil em pacientes e controles foi feita por meio de entrevista direta, durante a avaliação urológica, através de um questionário validado para a língua portuguesa. ${ }^{25}$ 


\subsection{Ultrassonografia testicular com doppler}

O exame foi realizado cegamente em relação aos resultados da análise do sêmen e avaliação urológica nos pacientes e controles. A maior medida em cada dimensão foi gravada e usada para calcular o volume testicular de acordo com a fórmula (comprimento $\mathrm{x}$ largura $\mathrm{x}$ espessura $\mathrm{x}$ 0,52). A média normal do volume testicular \pm desvio padrão (DP) em adolescentes do sexo masculino pós-púberes e adultos é de $15 \pm 8 \mathrm{ml}$. $^{11-13,26}$

\subsection{Avaliação hormonal}

As dosagens hormonais foram realizadas no início do estudo nos pacientes com SAF e controles, incuindo: FSH, hormônio luteinizante (LH), testosterona total matinal, triiodotironina (T3), tetraiodotironina (T4), fração livre da tetraiodotironina (T4 livre), e hormônio tireoestimulante (TSH) detectados por fluoroimunoensaio usando kit Delfia de fluoroimunoensaio (Wallac, Turku, Finlândia). Os coeficientes de variação intra e interensaio foram de $3,5 \%$ e $2,1 \%$, respectivamente. Os intervalos de variação para cada exame foram: FSH (1-10,5 UI/L), $\mathrm{LH}(1-8,4 \mathrm{UI} / \mathrm{L})$, testosterona matinal total $(271-965 \mathrm{ng} / \mathrm{dL})$, T3 $(7-20 \mathrm{ng} / \mathrm{dL}), \quad$ T4 $(4,5-12 \mathrm{mg} / \mathrm{dL})$, T4 livre (0,7-1,5 ng/dL) e TSH $(0,4-4,5 \mu \mathrm{U} / \mathrm{mL})$.

\subsection{Avaliação do sêmen}

A análise do sêmen foi realizada de acordo com as diretrizes da Organização Mundial de Saúde $(\mathrm{OMS})^{7}$ por dois técnicos peritos. Todos os pacientes e controles coletaram duas amostras de sêmen com intervalo de 
15-30 dias após 48-72 horas de abstinência sexual. Os espermatozóides foram analisados por contagem manual, bem como por um sistema de análise assistida por computador sob a ampliação de 400X, utilizando um aparelho HTM-2030. A motilidade dos espermatozóides foi classificada em "a" (motilidade progressiva rápida), "b" (motilidade progressiva lenta), "c" (motilidade não progressiva), e "d" (sem motilidade). A morfologia dos espermatozóides incluiu a avaliação das suas subdivisões (cabeça, pescoço, peça intermediária e cauda) seguindo critérios restritos da OMS e Kruger. $^{27}$ O paciente foi considerado como tendo azoospermia quando não foram encontrados espermatozóides na amostra e oligozoospermia quando a concentração de espermatozóides foi $<20$ milhões $/ \mathrm{mL} .{ }^{9}$ A presença de anticorpos antiespermatozóides foi determinada pelo teste direto de Immunobead utilizando kits de Imunoglobulina (Ig) anti-humana de coelho (IgA, IgG e IgM) Immunobead R (Irvine Scientific, Santa Ana, CA, EUA) em todos os pacientes e controles. Pelo menos $50 \%$ dos espermatozóides móveis ("a"+"b") devem ter "Immunobeads" aderidos para o teste ser considerado clinicamente significativo. Um controle negativo deve ter menos que $10 \%$ de "beads" aderidos enquanto que o controle positivo deve ter mais que $20 \%$ de "beads" aderidos. ${ }^{7}$

\subsection{Avaliação clínica e tratamento}

Os seguintes parâmetros clínicos foram avaliados nos pacientes com SAFP e SAF-LES: trombose venosa (documentada por trombose venosa profunda e/ou embolia pulmonar), trombose arterial (documentada 
por acidente vascular cerebral, ataque isquêmico transitório ou infarto agudo do miocárdio), livedo reticular e trombocitopenia (contagem menor que 100.000 plaquetas, pelo menos em duas ocasiões distintas). Nos pacientes com SAF-LES, foram também mensurados a atividade da doença, bem como seus danos cumulativos no momento do início do estudo, usando o Systemic Lupus Erythematosus Disease Activity Index (SLEDAl) ${ }^{28}$ e o Systemic Lupus International Collaborating Clinics/American College of Rheumatology Damage Index (SLICC/ACR-DI) ${ }^{29}$, respectivamente. Foram avaliados dados relativos ao tratamento como o uso prévio de CFEV.

\subsection{Análise imunológica}

Anticorpos anticardiolipina IgM e IgG foram detectados por um kit comercial (Kit imunoenzimático, BINDAZYME ${ }^{\mathrm{TM}}$, Birmingham, UK) em todos os pacientes com SAF. Os valores de corte foram: < 11GPL/MPL U/mL (negativo), $\geq 11$ e $<20 \mathrm{GPL} / \mathrm{MPL} \mathrm{U} / \mathrm{mL}$ (indeterminado) e $\geq 20 \mathrm{GPL} / \mathrm{MPL}$ $\mathrm{U} / \mathrm{mL}$ (positivo). ${ }^{30}$ Anticoagulante lúpico (LAC) foi detectado usando o tempo de tromboplastina parcial ativado (TTPA-Diagnostica Stago, França) e o tempo de veneno de víbora de Russel (dRVVT-Trinity Biotech, Wiclow, Irlanda, Reino Unido) de acordo com guidelines internacionais. ${ }^{31} \mathrm{O}$ anti-beta-2-glicoproteína I IgM e IgG foi detectado pela técnica de ELISA (ORG 521 anti-beta-2-glicoproteína I lgG/lgM Mainz, Alemanha), com valores de corte de $8 \mathrm{U} / \mathrm{mL}$ para $\operatorname{lgM}$ e $\lg$. Os coeficientes de variação foram de 2,1-5,0\% (intraensaio) e 2,6-7,95 (interensaio) para $\lg G$ e 2,1-3,8\% (intraensaio) e 4,1-6,3 (interensaio) para IgM. 


\subsection{Análise estatística}

Os dados foram comparados por testes $t$ ou teste de Mann-Whitney (dados com distribuição normal e anormal, respectivamente) para variáveis contínuas para avaliar as diferenças entre pacientes com SAFP, SAF-LES e controles, e em SAFP e SAF-LES de acordo com trombose arterial anterior, disfunção erétil e uso de CFEV. Para as variáveis categóricas, as diferenças foram avaliadas pelo teste exato de Fisher. Valores de "p" inferiores a 0,05 foram considerados significativos. 
4 RESULtAdOS 


\subsection{Pacientes SAFP versus controles}

Os dados demográficos, o IMC, a antropometria do pênis e o volume testicular pelo ultrassom em pacientes com SAFP e controles estão ilustrados na Tabela 1. A mediana da idade atual e idade da espermarca foi semelhante em ambos os grupos [37,5 (21-62) vs. 32,4 (18-54) anos, $\mathrm{p}=0,270 ; 13,1(12-16)$ vs. $12,85(11-15)$ anos, $\mathrm{p}=0,224$; respectivamente]. $\mathrm{O}$ IMC foi significantemente maior nos pacientes com SAFP comparado aos controles $\left[26,06(15,7-34,6)\right.$ vs. 22,2 $\left.(18-27) \mathrm{kg} / \mathrm{m}^{2}, \mathrm{p}=0,006\right]$. As medianas do comprimento e da circunferência do pênis foram iguais na SAFP comparados aos controles $[9,87$ (7-13) vs. 10 (8-13) cm, $\mathrm{p}=0,358$; 9 (6-11) vs. 9,4 (7-11) cm, p=0,185; respectivamente]. A disfunção erétil foi significantemente maior em pacientes com SAFP comparados aos controles $(25 \%$ vs. $0 \%, p=0,044)$. Não foram encontradas diferenças no volume testicular pela ultrassonografia em ambos os grupos $(p>0,05)$ (Tabela 1$)$.

A análise do sêmen, anticorpos antiespermatozóides e avaliação hormonal em pacientes com SAFP e controles estão apresentados na Tabela 2. Os parâmetros de esperma, anticorpos e hormônios foram semelhantes nos dois grupos $(p>0,05)$. Todos os pacientes SAFP e controles tinham dosagens de hormônios tireoidianos dentro da normalidade. 
Tabela 1 - Dados demográficos, índice de massa corpórea (IMC), antropometria do pênis e volume testicular por ultrassonografia em pacientes com síndrome antifosfolípide primária (SAFP), síndrome antifosfolípide associada ao lúpus eritematoso sistêmico (SAF-LES) e controles

\begin{tabular}{|c|c|c|c|c|c|c|}
\hline Variáveis & $\begin{array}{l}\text { SAFP } \\
(n=12)\end{array}$ & $\begin{array}{c}\text { SAF-LES } \\
(n=10)\end{array}$ & $\begin{array}{c}\text { Controles } \\
(n=20)\end{array}$ & $\mathbf{P}^{1}$ & $\mathbf{P}^{2}$ & $\mathbf{P}^{3}$ \\
\hline \multicolumn{7}{|l|}{ Dados demográficos e IMC } \\
\hline Idade atual, anos & $37,5(21-62)$ & $36,9(21-57)$ & $32,4(18-54)$ & 0,270 & 0,310 & 0,98 \\
\hline Idade do início da doença, anos & $31,41(18-61)$ & $32,20(14-57)$ & & & & 0,894 \\
\hline Duração da doença, anos & $6,08(1-18)$ & $5,73(0.3-13)$ & & & & 0,432 \\
\hline Idade da espermarca, anos & $13,1(12-16)$ & $13,9(12-16)$ & $12,85(11-15)$ & 0,224 & 0,016 & 0,17 \\
\hline Raça caucasiana & $6(50)$ & $4(40)$ & $7(33)$ & 0,473 & 1,0 & 0,691 \\
\hline $\mathrm{IMC}, \mathrm{Kg} / \mathrm{m}^{2}$ & $26,06(15,7-34,6)$ & $26,9(22-35,2)$ & $22,2(18-27)$ & 0,006 & 0,003 & 0,649 \\
\hline \multicolumn{7}{|c|}{ Antropometria do pênis e disfunção erétil } \\
\hline Comprimento, $\mathrm{cm}$ & $9,87(7-13)$ & $10,35(7,5-13)$ & $10,02(8-13)$ & 0,358 & 0,575 & 0,561 \\
\hline Circunferência, cm & $9(6-11)$ & $8,85(7-10,5)$ & $9,42(7-11)$ & 0,185 & 0,18 & 0,789 \\
\hline Disfunção erétil & $3(25)$ & $3(30)$ & 0 & 0,044 & 0,029 & 1,0 \\
\hline \multicolumn{7}{|l|}{ Volume testicular } \\
\hline Direito, $\mathrm{mL}$ & $12,85(7,2-18,4)$ & $10,38(3,9-16,7)$ & $13,41(8,5-20,6)$ & 0,68 & 0,030 & 0,154 \\
\hline Esquerdo, $\mathrm{mL}$ & $13,88(7,7-20)$ & $11,04(7,2-17,2)$ & $12,85(6-21,2)$ & 0,22 & 0,07 & 0,069 \\
\hline
\end{tabular}


Tabela 2 - Análise do sêmen, anticorpos antiespermatozóide e avaliação hormonal em pacientes com síndrome antifosfolípide primária (SAFP), síndrome antifosfolípide associada ao lúpus eritematoso sistêmico (SAF-LES) e controles

\begin{tabular}{|c|c|c|c|c|c|c|c|}
\hline Variáveis & $\begin{array}{l}\text { Valores de } \\
\text { referência }\end{array}$ & $\begin{array}{l}\text { SAFP } \\
(n=12)\end{array}$ & $\begin{array}{c}\text { SAF-LES } \\
(n=10)\end{array}$ & $\begin{array}{c}\text { Controles } \\
(n=20)\end{array}$ & $\mathbf{P}^{1}$ & $\mathbf{P}^{2}$ & $\mathbf{P}^{3}$ \\
\hline \multicolumn{8}{|l|}{ Análise do sêmen } \\
\hline Volume do sêmen, ml & $>2$ & $3,1 \pm 1,41$ & $2,95 \pm 1,16$ & $1,66 \pm 1,28$ & 0,25 & 0,35 & 0,77 \\
\hline Concentração de espermatozóides, $\times 10^{6} / \mathrm{ml}$ & $>20$ & $141,5(33-575)$ & $41,1(0-145)$ & $120,06(34,5-329)$ & 0,65 & 0,003 & 0,046 \\
\hline Oligo/azoospermia & & 0 & $4(40)$ & 0 & 1,0 & 0,007 & 0,029 \\
\hline Contagem total de espermatozóides $\times 10^{6}$ & $>40$ & $388(66-1131)$ & $142,2(0-471)$ & $300,5(41,3-1176)$ & 0,4 & 0,06 & 0,036 \\
\hline Motilidade de espermatozóides \% & $>50$ & $61,29(25-80)$ & $47,25(0-87,5)$ & $65,42(43-82)$ & 0,4 & 0,047 & 0,139 \\
\hline Espermatozóides normais (OMS) \% & $>15$ & $21,12(10-42,5)$ & $11(0-27)$ & $23,95(10-45)$ & 0,45 & 0,002 & 0,026 \\
\hline Espermatozóides normais (Kruger) \% & $>4$ & $5,79(1,5-16,5)$ & $2,65(0-8)$ & $7,65(3-18)$ & 0,27 & 0,02 & 0,06 \\
\hline Anticorpos antiespermatozóide \% & & $21,08(8-60)$ & $17,2(9-23)$ & $16,9(0-32)$ & 0,35 & 0,92 & 0,403 \\
\hline \multicolumn{8}{|l|}{ Avaliação hormonal } \\
\hline FSH, UI/litro & $1-10,5$ & $5,06(1-26,8)$ & $9,73(2,4-25)$ & $3,32(1-5,9)$ & 0,207 & 0,025 & 0,199 \\
\hline Níveis elevados & & $1(8)$ & $4(40)$ & 0 & 0,375 & 0,007 & 0,135 \\
\hline LH, UI/litro & $1-8,4$ & $4,48(1-13,1)$ & $6,87(1,6-21,7)$ & $3,49(1,8-5,8)$ & 0,171 & 0,074 & 0,327 \\
\hline Níveis elevados & & $1(8)$ & $2(20)$ & 0 & 0,375 & 0,103 & 0,571 \\
\hline Testosterona total, ng/dl & $271-965$ & $533(309-803)$ & $434,3(91-891)$ & $552,5(230-1078)$ & 0,381 & 0,09 & 0,242 \\
\hline Níveis reduzidos & & 0 & 0 & $1(5)$ & 1,0 & 1,0 & 1,0 \\
\hline
\end{tabular}

Valores expressos em média \pm desvio padrão, mediana (intervalo) ou $\mathrm{n}(\%), \mathrm{n}$ - número de pacientes e controles, OMS - Organização Mundial de Saúde, FSH - hormônio foliculoestimulante, LH - hormônio luteinizante, $\mathbf{P}^{1}$ - SAFP versus controles, $\mathbf{P}^{2}-$ SAF-LES versus controles, $\mathbf{P}^{3}-$ SAFP versus SAF-LES. 


\subsection{Pacientes SAFP}

A análise de subgrupos de pacientes com SAFP com $(n=7)$ e sem $(n=5)$ trombose arterial prévia demonstrou que a mediana da circunferência do pênis foi significantemente menor nos pacientes com eventos arteriais [8,1 (6-10) vs. $10,2(10-11) \mathrm{cm}, \mathrm{p}=0,007]$, enquanto a mediana do comprimento do pênis foi semelhante em ambos os grupos [9,1 (7-12) vs. $10,9(9,5-13) \mathrm{cm}, \mathrm{p}=0,08]$. Quarenta e dois por cento dos pacientes com SAFP e trombose arterial anterior tinham disfunção erétil em comparação com nenhum paciente do subgrupo sem evento arterial $(p=0,204)($ Tabela3 $)$.

A mediana da circunferência do pênis foi significantemente menor nos pacientes com SAFP com disfunção erétil $(n=3)$ comparado aos que não tiveram esta alteração $(n=9)[7,5(6-9,5)$ vs. $9,5(7,5-11) \mathrm{cm}, \mathrm{p}=0,039]$. Nenhuma diferença foi evidenciada na mediana do comprimento do pênis nos dois grupos $[8,33(7-11,5)$ vs. $10,22(8-13) \mathrm{cm}, \mathrm{p}=0,280]$. Os dados demográficos, IMC, volume testicular pelo ultrassom, análise do sêmen, anticorpos antiespermatozóides, perfil hormonal e características clínicas e laboratoriais foram semelhantes em pacientes com SAFP com e sem eventos arteriais ( $p>0,05$; Tabela 3$)$. 
Tabela 3 - Dados demográficos, índice de massa corpórea (IMC), antropometria do pênis, volume testicular por ultrassonografia, análise do sêmen, anticorpos antiespermatozóide, avaliação hormonal e características clínicas e laboratoriais no início do estudo em pacientes com síndrome antifosfolípide primária (SAFP) com e sem eventos arteriais anteriores.

\begin{tabular}{|c|c|c|c|c|}
\hline Variáveis & $\begin{array}{c}\text { Valores } \\
\text { de } \\
\text { referência }\end{array}$ & $\begin{array}{c}\text { SAFP } \\
\text { Com evento } \\
\text { arterial } \\
(n=7)\end{array}$ & $\begin{array}{c}\text { SAFP } \\
\text { Sem evento } \\
\text { arterial } \\
(n=5)\end{array}$ & $\mathbf{P}$ \\
\hline \multicolumn{5}{|l|}{ Dados demográficos e IMC } \\
\hline Idade atual, anos & & $40,7(24-62)$ & $33(21-53)$ & 0,334 \\
\hline Duração da doença, anos & & $6,1(1-16)$ & $6(2-18)$ & 0,969 \\
\hline Idade da espermarca, anos & & $13,5(12-16)$ & $12,6(12-13)$ & 0,1 \\
\hline Raca caucasiana & & $3(42)$ & $1(20)$ & 0,417 \\
\hline $\mathrm{IMC}, \mathrm{Kg} / \mathrm{m}^{2}$ & & $27,2(24-34,6)$ & $24,4(15,7-27,7)$ & 0,27 \\
\hline \multicolumn{5}{|l|}{$\begin{array}{l}\text { Antropometria do pênis e disfunção } \\
\text { erétil }\end{array}$} \\
\hline Comprimento, $\mathrm{cm}$ & & $9,1(7-12)$ & $10,9(9,5-13)$ & 0,08 \\
\hline Circunferência, cm & & $8,1(6-10)$ & $10,2(10-11)$ & 0,007 \\
\hline Disfunção erétil & & $3(42)$ & 0 & 0,204 \\
\hline Volume testicular & $15 \pm 8 \mathrm{ml}$ & & & \\
\hline Direito, $\mathrm{mL}$ & & $12,5(7,2-17)$ & $13,3(8,2-18,4)$ & 0,738 \\
\hline Esquerdo, $\mathrm{mL}$ & & $13,7(7,7-20)$ & $14(12-17)$ & 0,902 \\
\hline \multicolumn{5}{|l|}{ Análise do sêmen } \\
\hline Volume do sêmen, ml & $>2$ & $3,1(1,5-6,8)$ & $3,1(2,5-3,5)$ & 0985 \\
\hline $\begin{array}{l}\text { Concentração de espermatozóides } x \\
10^{6} / \mathrm{ml}\end{array}$ & $>20$ & $156(33-575)$ & $121,1(55-255)$ & 0,674 \\
\hline Contagem total de espermatozóides $\times 10^{6}$ & $>40$ & $416(66-1131)$ & $348,8(165-637)$ & 0,74 \\
\hline Motilidade de espermatozóides,\% & $>50$ & $58,2(25-65)$ & $65,6(40-80)$ & 0,419 \\
\hline $\begin{array}{l}\text { Morfologia normal dos espermatozóides } \\
\text { (OMS),\% }\end{array}$ & $>15$ & $21,2(10-42,5)$ & $20,9(13,5-33)$ & 0,95 \\
\hline $\begin{array}{l}\text { Morfologia normal dos espermatozóides } \\
\text { (Kruger),\% }\end{array}$ & $>4$ & $6,28(1,5-16,5)$ & $5,1(1,5-10)$ & 0,655 \\
\hline Anticorpos antiespermatozóide, \% & $>50 \%$ & $25,7(8-60)$ & $14,6(11-17)$ & 0,164 \\
\hline \multicolumn{5}{|l|}{ Avaliação hormonal } \\
\hline FSH, UI//itro & $1-10,5$ & $6,24(0,8-26,8)$ & $3,38(1,3-5,3)$ & 0,451 \\
\hline Níveis elevados & & $1(14)$ & $3(60)$ & 0,222 \\
\hline LH, UI/litro & $1-8,4$ & $4,65(1-13,1)$ & $4,24(2,6-8)$ & 0,82 \\
\hline Níveis elevados & & $1(14)$ & 0 & 1,0 \\
\hline Testosterona total, ng/dl & 271-965 & $522,4(417-622)$ & $547,8(309-803)$ & 0,78 \\
\hline Níveis diminuídos & & 0 & 0 & 1,0 \\
\hline \multicolumn{5}{|l|}{ Características clínicas e laboratoriais, \% } \\
\hline Plaquetopenia & & 0 & 0 & 1,0 \\
\hline Livedo reticular & & 0 & 0 & 1,0 \\
\hline Anticardiolipina IgM, MPL U/mL & $\geq 20$ & $2(28)$ & $1(20)$ & 1,0 \\
\hline Anticardiolipina IgG, GPL U/mL & $\geq 20$ & $1(14)$ & $1(20)$ & 1,0 \\
\hline Anticoagulante lúpico & & $3(42)$ & $5(100)$ & 0,08 \\
\hline Anti-beta2-glicoproteina I IgM, U/mL & $>8$ & $2(28)$ & $1(20)$ & 1,0 \\
\hline Anti-beta2-glicoproteina I lgG, $\mathrm{U} / \mathrm{mL}$ & $>8$ & $3(42)$ & $1(20)$ & 0,575 \\
\hline
\end{tabular}

Valores expressos em mediana (intervalo) ou $\mathrm{n}(\%), \mathrm{n}$ - número de pacientes e controles, OMS - Organização Mundial de Saúde, FSH - hormônio folículoestimulante, LH - hormônio luteinizante. 


\subsection{Pacientes SAF-LES versus controles}

A mediana da idade da espermarca foi significantemente maior no grupo de SAF-LES comparado aos controles [13,9 (12-16) vs. 12,85 (11-15) anos, $p=0,016]$. Por sua vez, a mediana do volume testicular direito por ultrassom foi menor no SAF-LES $[10,38(3,9-16,7)$ vs. $13,4(8,5-20,6) \mathrm{ml}$, $p=0,03]$. A frequência de disfunção erétil foi significantemente maior nos pacientes com SAF-LES comparado aos controles ( $30 \%$ vs. $0 \%, \mathrm{p}=0,029)$. Não foram observadas diferenças em relação à antropometria do pênis e ao volume testicular esquerdo em ambos os grupos (Tabela 1). As medianas da concentração e da motilidade dos espermatozóides foram significantemente menores nos pacientes com SAF-LES comparados aos controles $[41,1$ $(0-145)$ vs. $120,06(34,5-329) \times 10^{6} / \mathrm{mL}, \mathrm{p}=0,003 ; 47,25(0-87,5)$ vs. 65,42 (43-82) \%, p=0,047; respectivamente]. As formas de espermatozóides normais avaliados pela OMS e Kruger foram significantemente menores no SAF-LES que nos controles [11 (0-27) vs. 23,95 (10-45)\%, $\mathrm{p}=0,002 ; 2,65$ $(0-8)$ vs. $7,65 \quad(3-18) \%, \quad p=0,02$; respectivamente]. A frequência de oligo/azoospermia foi significantemente maior no grupo SAF-LES (40\% vs. 0\%, $p=0,007$ ). Da mesma forma, a mediana dos níveis de $\mathrm{FSH}$ e as frequências de FSH elevados foram significantemente maiores nesse grupo $[9,73(2,4-25)$ vs. $3,32 \quad(1-5,9) \quad \mathrm{Ul} / \mathrm{L}, \mathrm{p}=0,025 ; 40 \%$ vs.0\%, $\mathrm{p}=0,007 ;$ respectivamente] (Tabela 2). Todos os pacientes com SAF-LES e controles tinham dosagens de hormônios tireoidianos normais. 


\subsection{Pacientes SAF-LES}

A análise de subgrupos de SAF-LES com $(n=2)$ e sem $(n=8)$ eventos arteriais prévios demonstrou que a mediana da circunferência peniana foi significantemente menor nos que tiveram trombose arterial [7,5 (7-8) vs. 9,18 $(8-10,5) \mathrm{cm}, \mathrm{p}=0,039]$, com mediana de comprimento semelhante em ambos os grupos $[8,25(7,5-9)$ vs. $10,87(8,5-13) \mathrm{cm}, \mathrm{p}=0,08]$ (Tabela 4).

A mediana da circunferência do pênis foi significantemente menor no subgrupo de SAF-LES com disfunção erétil $(n=3)$ versus sem essa alteração $(\mathrm{n}=7)[8,17(8-8,5)$ vs. $9,14(7-10,5) \mathrm{cm}, \mathrm{p}=0,0397]$. Nenhuma diferença foi evidenciada na mediana do comprimento do pênis em ambos os grupos $[10,83(9-12,5)$ vs. $10,14(7,5-13) \mathrm{cm}, \mathrm{p}=0,615]$.

Os dados demográficos, IMC, volume testicular pelo ultrassom, análise do sêmen, perfil hormonal e características clínicas e laboratoriais foram semelhantes nos pacientes SAF-LES com e sem eventos arteriais prévios $(p>0,05)$ (Tabela 4).

A CFEV foi usada para o tratamento de nefrite lúpica em quatro pacientes. A mediana de tempo de duração entre a última dose de CFEV e o início do estudo foi de seis anos (variação de 2 a 9 anos). A mediana de duração da doença foi significativamente maior nos doentes tratados com CFEV $(n=4)$ em comparação aos que não receberam essa medicação $(n=6)$ [9,92 (5-13) vs. 3,38 (0,3-7) anos, $\mathrm{p}=0,028]$. As medianas da concentração e da contagem de total de espermatozóides foram significantemente menores 
no SAF-LES tratados com CFEV comparado aos que não usaram essa medicação $[6,87(0-23,5)$ vs. 63,9 (7,5-145) x 106/mL, $\mathrm{p}=0,04 ; 16,12(0-55,5)$ vs. $226,25(8,5-471) \times 10^{6}, \mathrm{p}=0,035$; respectivamente]. Não foram observadas diferenças na antropometria do pênis, volume testicular por ultrassom, anticorpos antiespermatozóide, perfil hormonal, atividade e dano cumulativo da doença em ambos os grupos ( $p>0,05)$ (Tabela5). 
Tabela 4 - Dados demográficos, índice de massa corpórea (IMC), antropometria do pênis, volume testicular por ultrassonografia, análise do sêmen, anticorpos antiespermatozóide, avaliação hormonal, características clínicas e laboratoriais no início do estudo, atividade e dano cumulativo da doença em pacientes com síndrome antifosfolípide associada ao lúpus eritematoso sistêmico (SAF-LES) com e sem eventos arteriais anteriores.

\begin{tabular}{|c|c|c|c|c|}
\hline Variáveis & $\begin{array}{c}\text { Valores } \\
\text { de } \\
\text { referência }\end{array}$ & $\begin{array}{c}\text { SAF-LES } \\
\text { Com evento } \\
\text { arterial } \\
(n=2)\end{array}$ & $\begin{array}{c}\text { SAF-LES } \\
\text { Sem evento } \\
\text { arterial } \\
(\mathbf{n}=\mathbf{8})\end{array}$ & $\mathbf{P}$ \\
\hline \multicolumn{5}{|l|}{ Dados demográficos e IMC } \\
\hline Idade atual, anos & & $39,5(37-42)$ & $36,25(21-57)$ & 0,538 \\
\hline Duração da doença, anos & & $5,5(1-10)$ & $5,78(2-13)$ & 0,935 \\
\hline Idade da espermarca, anos & & $14(13-15)$ & $13,87(12-16)$ & 0,904 \\
\hline Raça caucasiana & & $1(50)$ & $2(25)$ & 1,0 \\
\hline $\mathrm{IMC}, \mathrm{Kg} / \mathrm{m}^{2}$ & & $31,1(27-35,2)$ & $25,87(22-31,3)$ & 0,132 \\
\hline \multicolumn{5}{|l|}{ Antropometria do pênis e disfunção erétil } \\
\hline Comprimento, $\mathrm{cm}$ & & $8,25(7,5-9)$ & $10,87(8.5-13)$ & 0,08 \\
\hline Circunferência, cm & & $7,5(7-8)$ & $9,18(8-10.5)$ & 0,039 \\
\hline Disfunção erétil & & $1(50)$ & $2(25)$ & 1,0 \\
\hline Volume testicular & $15 \pm 8 \mathrm{ml}$ & & & \\
\hline Direito, $\mathrm{mL}$ & & $7,2(4,8-9,6)$ & $11,17(3,9-16,7)$ & 0,213 \\
\hline Esquerdo, $\mathrm{mL}$ & & $9,15(8,9-9,4)$ & $11,51(7,2-17,2)$ & 0,082 \\
\hline \multicolumn{5}{|l|}{ Análise do semen } \\
\hline Volume do sêmen, ml & $>2$ & $3,5(3,5-3,5)$ & $2,81(1,5-4,5)$ & 0,086 \\
\hline Concentração de espermatozóides, $\times 10^{6} / \mathrm{ml}$ & $>20$ & $53(2-104)$ & $38,12(0-145)$ & 0,721 \\
\hline Oligo/azoospermia & & $1(50)$ & $3(37)$ & 1,0 \\
\hline Contagem total de espermatozóides, $\times 10^{6}$ & $>40$ & $211(6-416)$ & $125(0-471)$ & 0,562 \\
\hline Motilidade de espermatozóides,\% & $>50$ & $26(16-36)$ & $52,6(0-87,5)$ & 0,143 \\
\hline Espermatozóides norn & $>15$ & $9,5(5-14)$ & $11,37(0-27)$ & 0,769 \\
\hline Esperm & $>4$ & $2,75(1,5-4)$ & $2,62(0-8)$ & 0,943 \\
\hline $\begin{array}{l}\text { Anticorpos antiespermatozóide, \% } \\
\text { Avaliação hormonal }\end{array}$ & $>50 \%$ & $17,5(12-23)$ & $17,12(9-21)$ & 0,918 \\
\hline FSH, Ul//itro & $1-10,5$ & $8,7(4,2-13,2)$ & $9,98(2,4-25)$ & 0,839 \\
\hline Níveis elevados & & $1(50)$ & $3(37)$ & 1,0 \\
\hline LH, UI/litro & $1-8,4$ & $5,95(3,1-8,8)$ & $7,1(1,6-21,7)$ & 0,786 \\
\hline Níveis elevados & & $1(50)$ & $2(25)$ & 1,0 \\
\hline Testosterona total, ng/dl & $271-965$ & $427,5(321-534)$ & $436(91-891)$ & 0,955 \\
\hline Níveis diminuídos & & 0 & $2(25)$ & 1,0 \\
\hline \multicolumn{5}{|l|}{ Características clínicas e laboratoriais, \% } \\
\hline Plaquetopenia & & 0 & 0 & 1,0 \\
\hline Livedo reticular & & 0 & 0 & 1,0 \\
\hline AnticardiolipinalgM, MPL U/mL & $\geq 20$ & $1(50)$ & $2(25)$ & 1,0 \\
\hline $\operatorname{lgG}, \mathrm{GPL} U / \mathrm{mL}$ & $\geq 20$ & $2(100)$ & $4(50)$ & 0,466 \\
\hline Antic & & $1(50)$ & $5(62)$ & 1,0 \\
\hline Anti-beta2-glicoproteina I IgM, U/mL & $>8$ & 0 & $2(25)$ & 1,0 \\
\hline Anti-beta2-glicoproteina I lgG, U/mL & $>8$ & $1(50)$ & $2(25)$ & 1,0 \\
\hline \multicolumn{5}{|l|}{ Atividade e dano cumulativo da doença } \\
\hline SLEDAI & & $0(0-0)$ & $2,65(0-12)$ & 0,054 \\
\hline SLICC/ACR-DI & & $1(1-1)$ & $0,62(0-4)$ & 0,237 \\
\hline
\end{tabular}

Valores expressos em mediana (intervalo) ou $\mathrm{n}(\%), \mathrm{n}$ - número de pacientes e controles, OMS - Organização Mundial de Saúde, FSH - hormônio foliculoestimulante, LH - hormônio luteinizante, SLEDAI - Systemic Lupus Erythematosus Disease Activity Index, SLICC/ACR-DI Systemic Lupus International Collaborating Clinics/American College of Rheumatology Damage Index. 
Tabela 5 - Dados demográficos, índice de massa corpórea (IMC), antropometria do pênis, volume testicular por ultrassonografia, análise do sêmen, anticorpos antiespermatozóide, avaliação hormonal, atividade e dano cumulativo da doença em pacientes com síndrome antifosfolípide associada ao lúpus eritematoso sistêmico (SAF-LES), tratados ou não com ciclofosfamida endovenosa (CFEV).

\begin{tabular}{|c|c|c|c|c|}
\hline Variáveis & $\begin{array}{l}\text { Valores } \\
\text { de } \\
\text { referência }\end{array}$ & $\begin{array}{c}\text { SAF-LES } \\
\text { Com CFEV } \\
(n=4)\end{array}$ & $\begin{array}{c}\text { SAF-LES } \\
\text { Sem CFEV } \\
(n=6)\end{array}$ & $\mathbf{P}$ \\
\hline \multicolumn{5}{|l|}{ Dados demográficos e IMC } \\
\hline Idade atual, anos & & $35(23-47)$ & $38,16(21-57)$ & 0,683 \\
\hline Duração da doença, anos & & $9,92(5-13)$ & $3,38(0,3-7)$ & 0,028 \\
\hline Idade da espermarca, anos & & $13,20(12-14)$ & $14,33(13-16)$ & 0,156 \\
\hline Raça caucasiana & & $1(25)$ & $3(50)$ & 0,571 \\
\hline $\mathrm{IMC}, \mathrm{Kg} / \mathrm{m}^{2}$ & & $25(22-27)$ & $28,2(23,5-35,2)$ & 0,218 \\
\hline \multicolumn{5}{|l|}{ Antropometria do pênis e disfunção erétil } \\
\hline Comprimento, $\mathrm{cm}$ & & $9,0(7,5-11)$ & $11,08(8,5-13)$ & 0,135 \\
\hline Circunferência, cm & & $8,5(7,0-10)$ & $9,08(8-10,5)$ & 0,147 \\
\hline Disfunção erétil & & $1(25)$ & $2(33)$ & 1,0 \\
\hline Volume testicular & $15 \pm 8 \mathrm{ml}$ & & & \\
\hline Direito, mL & & $7,77(3,9-12,4)$ & $12,11(9,1-16,7)$ & 0,125 \\
\hline Esquerdo, $\mathrm{mL}$ & & $9,9(7,2-13)$ & $11,8(7,8-17,2)$ & 0,33 \\
\hline \multicolumn{5}{|l|}{ Análise do sêmen } \\
\hline Volume do sêmen, $\mathrm{ml}$ & $>2$ & $2,25(1,5-3,5)$ & $3,41(1,5-4,5)$ & 0,119 \\
\hline Concentração de espermatozóides $\times 10^{6} / \mathrm{ml}$ & $>20$ & $6,87(0-23,5)$ & $63,9(7,5-145)$ & 0,04 \\
\hline Oligo/azoospermia & & $3(75)$ & $1(16)$ & 0,19 \\
\hline Contagem total de espermatozóides $\times 10^{6}$ & $>40$ & $16,12(0-55.5)$ & $226,25(8,5-471)$ & 0,035 \\
\hline Motilidade de espermatozóides,\% & $>50$ & $29,87(0-55)$ & $59,5(36-87,5)$ & 0,11 \\
\hline Espermatozóides normais (OMS),\% & $>15$ & $6,75(0-20)$ & $13,83(4-27)$ & 0,264 \\
\hline Espermatozóides normais (Kruger),\% & $>4$ & $1,75(0-5)$ & $3,25(1-8)$ & 0,367 \\
\hline Anticorpos antiespermatozóide, \% & $>50 \%$ & $19(17-23)$ & $16(9-21)$ & 0,251 \\
\hline \multicolumn{5}{|l|}{ Avaliação hormonal } \\
\hline FSH, Ul/litro & $1-10,5$ & $13,92(4,3-25)$ & $6,93(2,4-24,9)$ & 0,251 \\
\hline Níveis elevados & & $3(75)$ & $1(16)$ & 0,195 \\
\hline LH, UI/litro & $1-8,4$ & $8,57(3,3-15,6)$ & $5,73(1,6-21,7)$ & 0,51 \\
\hline Níveis elevados & & $2(50)$ & $1(16)$ & 0,5 \\
\hline Testosterona total, ng/dl & $271-965$ & $387,2(91-891)$ & $465,66(322-586)$ & 0,689 \\
\hline Níveis diminuídos & & $2(50)$ & 0 & 0,133 \\
\hline \multicolumn{5}{|l|}{ Atividade e dano cumulativo da doença } \\
\hline SLEDAI & & $2,5(0-6)$ & $2,33(0-8)$ & 0,467 \\
\hline SLICC/ACR-DI & & $1,25(0-4)$ & $0,33(0-1)$ & 0,207 \\
\hline
\end{tabular}




\subsection{Pacientes SAFP versus SAF-LES}

As medianas de concentração, contagem total e formas normais de espermatozóides foram significantemente maiores nos pacientes SAFP comparados ao SAF-LES $\left[141,5(33-575)\right.$ vs. $41,1(0-145) \times 10^{6} / \mathrm{mL}$, $\mathrm{p}=0,046 ; 388 \quad(66-1131) \quad$ vs. $142,2(0-471) \times 10^{6}, \mathrm{p}=0,036 ; 21,12$ $(10-42,5)$ vs. $11 \quad(0-27) \%, p=0,026$; respectivamente]. A frequência de oligo/azoospermia foi significantemente menor no grupo SAFP versus SAF-LES ( $0 \%$ vs. $40 \%, p=0,029)$. Não foram observadas diferenças em dados demográficos, antropometria do pênis, volume testicular e perfil hormonal em ambos os grupos $(p>0,05)$ (Tabelas 1 e 2$)$. 
5 DISCUSSÃO 
Este foi o primeiro estudo que abordou especificamente a função gonadal em pacientes com SAFP e SAF-LES em relação a controles saudáveis, mostrando claramente que estes pacientes têm diminuição das dimensões penianas relacionados à trombose arterial anterior. A antropometria do pênis anormal com disfunção erétil foi evidenciada nesses pacientes. Também foram verificadas importantes anormalidades nos espermatozóides em pacientes com SAF-LES que receberam CFEV.

A grande vantagem do presente estudo foi a avaliação sistemática peniana e testicular através de critérios estabelecidos para a antropometria do pênis, ${ }^{16,24}$ avaliações dos espermatozóides e anticorpos antiespermatozóides, ${ }^{5,6}$ e a inclusão apenas de pacientes pós-púberes e controles saudáveis. Além disso, a seleção dos pacientes com SAF e controles sem anormalidades testiculares e comorbidades é de extrema importância uma vez que estas alterações podem causar alterações gonadais. ${ }^{6}$

O desenvolvimento das dimensões do pênis ocorre apenas durante a puberdade e pode ser influenciado pela herança genética, disfunção do eixo hipotálamo-hipofisário e doenças crônicas, como descrito em nossos pacientes com LES. ${ }^{5,16}$ A produção de andrógenos pelos testículos e glândulas suprarrenais durante a puberdade é provavelmente 0 fator mais importante para o desenvolvimento dos órgãos genitais, como o pênis. ${ }^{32}$ Todos os nossos pacientes SAFP e SAF-LES com redução da antropometria peniana tiveram início da doença após a espermarca, indicando que esta alteração não foi atribuída ao desenvolvimento puberal 
durante a adolescência. Em contrapartida, nós observamos medianas reduzidas de circunferência peniana em pacientes lúpicos sem SAF associada pré-púberes em relação aos pacientes pós-púberes. ${ }^{16}$ Curiosamente os pacientes com SAFP e SAF-LES que tiveram tromboses arteriais prévias apresentaram diminuição das dimensões penianas, sugerindo que, além da trombose arterial dominante, microtrombos também podem ser instalados em outros órgãos, como o pênis e o corpo cavernoso. ${ }^{33}$ Vale a pena ressaltar que todos os pacientes eram assintomáticos com relação ao pênis, sem edema e/ou dor. Não existem relatos de casos de trombose peniana em pacientes com SAF.

Notadamente, a disfunção erétil ocorreu nos pacientes com SAFP e SAF-LES com redução da circunferência do pênis. Essa disfunção sexual é caracterizada pela incapacidade do homem para conseguir uma ereção e mantê-la suficientemente razoável para $\mathrm{o}$ ato sexual. ${ }^{34} \mathrm{~A}$ impotência sexual também foi relatada recentemente por nosso grupo em uma pequena população de SAF ligados à eventos arteriais, ${ }^{35}$ no entanto as avaliações do pênis e dos testículos não foram realizados neste estudo. Anormalidades morfofuncionais do pênis em nossos pacientes com SAF, sem dúvida, podem provocar preocupações psicológicas e alteração na sua qualidade de vida relacionada à saúde. ${ }^{34}$ Entretanto, apenas os homens com um comprimento flácido do pênis menor que quatro centímetros devem ser considerados candidatos para o aumento do pênis e nenhum dos nossos pacientes tinha micropênis. ${ }^{36}$ 
Além disso, no grupo de SAF-LES, confirmamos nossa observação anterior de anormalidades no esperma, redução do volume testicular $^{11-13,16}$ e alterações hormonais em homens com LES sem SAF associada. $^{11-13} \mathrm{O}$ uso de ciclofosfamida parece contribuir para alterações importantes do sêmen em nossos pacientes SAF-LES ocasionando um dano persistente ou de longa duração para as células gonadais, como também observado em homens com LES sem SAF. ${ }^{12}$

Não há explicação clara para o atraso da espermarca nos pacientes SAF-LES, não sendo influenciado pela atividade da doença e/ou drogas, uma vez que todos eles tiveram o início da doença após a primeira ejaculação. Ao contrário, nós demonstramos anteriormente ocorrência tardia da menarca em paciente com LES juvenil ${ }^{37-39}$ e dermatomiosite juvenil ${ }^{40}$ nas quais a doença ocorreu antes da primeira menstruação, em comparação com adolescentes brasileiros saudáveis.

Este estudo enfatiza a importância da criopreservação de esperma para técnicas futuras de reprodução assistida antes de usar CFEV. ${ }^{6}$ Além disso, nossos pacientes com SAFP tinha função gonadal normal, sendo que trombose testicular foi raramente relatado na literatura nestes pacientes. ${ }^{4}$

O seguimento destes pacientes está sendo realizado no Centro de Reprodução Humana do HC-FMUSP. A abordagem multidisciplinar e multiprofissional da infertilidade e disfunção erétil é fundamental para estes pacientes, melhorando a sua qualidade de vida relacionada à saúde e de suas respectivas parceiras. Outros estudos avaliando a função sexual, 
envolvimento da vasculatura peniana e eficácia/segurança das drogas para disfunção erétil (inibidores de fosfodiesterase tipo 5) serão realizados futuramente nesta população de pacientes com trombose autoimune. 
6 Conclusões

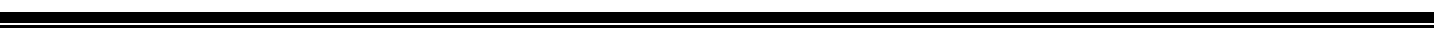


1 Pacientes com SAFP e SAF-LES apresentaram redução do tamanho do pênis associada à trombose arterial anterior e à disfunção erétil.

2 Pacientes com SAF-LES tiveram disfunção testicular devido ao uso de agentes alquilantes. 


\section{REFERÊNCIAS}


1. de Groot PG, Derksen RH, de Laat B. Twenty-two years of failure to set up undisputed assays to detect patients with the antiphospholipid syndrome. Semin Thromb Hemost 2008; 34: 347-355.

2. Cervera R, Khamashta MA, Shoenfeld $\mathrm{Y}$, et al. Morbidity and mortality in the antiphospholipid syndrome during a 5-year period: a multicentre prospective study of 1000 patients. Ann Rheum Dis 2009; 68: 1428-1432.

3. Mejía-Romero R, García-Carrasco M, Galarza-Maldonado C, et al. Primary antiphospholipid syndrome in Latin American mestizo patients: clinical and immunologic characteristics and comparison with European patients. Clin Rheumatol 2008; 27: 891-897.

4. Mehdi AA, Salti I, Uthman I. Antiphospholipid syndrome: endocrinologic manifestations and organ involvement. Semin Thromb Hemost 2011; 37: 49-57.

5. Silva CA, Brunner $\mathrm{HI}$. Gonadal functioning and preservation of reproductive fitness with juvenile systemic lupus erythematosus. Lupus 2007; 16: 593-599.

6. Silva CA, Bonfa E, Ostensen M. Maintenance of fertility in patients with rheumatic diseases needing anti-inflammatory and immunosuppressive drugs. Arthritis Care Res (Hoboken) 2010; 62: 1682-1690. 
7. Rowe PJ, Comhaire FH, Hargreave TB, Mahmoud AM. World Health Organization $(\mathrm{WHO})$ for the standardized investigation, diagnosis and management of the infertile men. $1^{\text {st }}$ ed. Cambridge: Cambridge University Press; 2000: 1-86.

8. Shefi S, Turek PJ. Definition and current evaluation of subfertile men. Int Braz J Urol 2006; 32: 385-397.

9. Østensen $M$, Lockshin $M$, Doria $A$, et al. Update on safety during pregnancy of biological agents and some immunosuppressive anti-rheumatic drugs. Rheumatology (Oxford) 2008; 47: 28-31.

10. Ostensen M, Brucato A, Carp H, et al. Pregnancy and reproduction in autoimmune rheumatic diseases. Rheumatology (Oxford) 2011; 50: 657-664.

11. Silva CA, Hallak J, Pasqualotto FF, Barba MF, Salto MI, Kiss MH. Gonadal function in adolescents and young men with systemic lupus erythematosus. J Rheumatol 2002; 29: 2000-2005.

12. Soares PM, Borba EF, Bonfa E, Hallak J, Corrêa AL, Silva CA. Gonad evaluation in male systemic lupus erythematosus. Arthritis Rheum 2007; 56: 2352-2361. 
13. Suehiro RM, Borba EF, Bonfa E, et al. Testicular Sertoli cell function in male systemic lupus erythematosus. Rheumatology (Oxford) 2008; 47: 1692-1697.

14. Moraes AJ, Pereira RM, Cocuzza M, Casemiro R, Saito O, Silva CA. Minor sperm abnormalities in young male post-pubertal patients with juvenile dermatomyositis. Braz J Med Biol Res 2008, 41: 1142-1147.

15. Moraes AJ, Pereira RM, Cocuzza M, Casemiro R, Saito O, Silva CA. Gonad evaluation in male dermatomyositis. A pilot study. Clin Exp Rheumatol 2010; 28: 441-442.

16. Vecchi A, Borba E, Bonfá E, et al. Penile anthropometry in systemic lupus erythematosus patients. Lupus 2011; 20: 512-518.

17. Wu VH, Dangman BC, Kaufman RP Jr. Sonographic appearance of acute testicular venous infarction in a patient with a hypercoagulable state. $J$ Ultrasound Med 1995; 14: 57-59.

18. Leder AN, Flansbaum B, Zandman-Goddard G, Asherson R, Shoenfeld Y. Antiphospholipid syndrome induced by HIV. Lupus 2001; 10: 370-374.

19. Göbel U, Kettritz R, Schneider W, Luft FC. A particularly private pain. Nephrol Dial Transplant 2002; 17: 516-518. 
20. Fernández Rosado E, Sánchez Rodríguez-Losada J, Alvarez Castelo L, et al. Urologic damage of the primary antiphospholipid syndrome. Arch Esp Urol 2004; 57: 707-723.

21. Uthman I, Salti I, Khamashta M. Endocrinologic manifestations of the antiphospholipid syndrome. Lupus 2006; 15: 485-489.

22. Wilson WA, Gharavi AE, Koike $\mathrm{T}$, et al. International consensus statement on preliminary classification criteria for definite antiphospholipid syndrome: report of an international workshop. Arthritis Rheum 1999; 42: 1309-1311.

23. Tanner JM. Growth at adolescence. 2nd edition. Oxford: Blackwell Scientific Publications, 1962.

24. Ponchietti R, Mondaini N, Bonafè M, Di Loro F, Biscioni S, Masieri L. Penile length and circumference: a study on 3.300 young Italian males. Eur Urol 2001; 39: 183-186.

25. Abdo $\mathrm{CH}$. The male sexual quotient: a brief, self-administered questionnaire to assess male sexual satisfaction. J Sex Med 2007; 4:382-389. 
26. Atkinson GO, Patrick LE, Ball TI. The normal and abnormal scrotum in children: evaluation with color Doppler sonography. Am J Roentgenol 1992; 158: 613-617.

27. Kruger TF, Acosta AA, Simmons KF, Swanson RJ, Matta JF, Oehninger S. Predictive value of abnormal sperm morphology in vitro fertilization. Fertil Steril 1988; 49: 112-117.

28. Bombardier C, Gladman DD, Urowitz MB, Karon D, Chang $\mathrm{CH}$ and The Committee on Prognosis Studies in SLE. Derivation of the SLEDAI: a disease activity index for lupus patients. Arthritis Rheum 1992; 35: 630-640.

29. Gladman D, Ginzler E, Goldsmith C, et al. The development and initial validation of the Systemic Lupus International Collaborating Clinics/American College of Rheumatology Damage Index for systemic lupus erythematosus. Arthritis Rheum 1996; 39: 363-369.

30. Haris EN, Pierangeli S, Birch D. Cardiolipin Wet Workshop report. Am J Clin Path 1994, 101: 616-624.

31. Wisloff F, Jacobsen EM, Liestol S. Laboratory diagnosis of the antiphospholipid syndrome. Thromb Res 2002; 108: 263-271. 
32. Dohle GR, Smit M, Weber RF. Androgens and male fertility. World J Urol 2003; 21: 341-345.

33. Patel RP, Mucksavage P, Ramchandani P, Hanno PM, Malkowicz SB. Idiopathic partial thrombosis of the corpus cavernosum. Urology 2010; 76:1373-1374.

34. Araujo DB, Borba EF, Abdo $\mathrm{CH}$, et al. Sexual function in rheumatic diseases. Acta Reumatol Port 2010; 35: 16-23.

35. Gallinaro AL, Silva CA, Rabelo-Junior CN, Caleiro MT, Carvalho JF. Moderate/severe erectile dysfunction in patients with antiphospholipid syndrome. Lupus 2011 (published online).

36. Wessells H, Lue TF, McAninch JW. Penile length in the flaccid and erect states: guidelines for penile augmentation. J Urol 1996; 156: 995-997.

37. Silva CA, Leal MM, Leone C, Simone VP, Takiuti AD, Saito Ml, et al. Gonadal function in adolescents and young female with systemic lupus erythematosus. Lupus 2002; 11: 419-425.

38. Febronio MV, Pereira RM, Bonfa E, Takiuti AD, Pereyra EA, Silva CA. Inflammatory cervicovaginal cytology is associated with disease activity in juvenile systemic lupus erythematosus. Lupus 2007; 16: 430-543. 
39. Medeiros PB, Febrônio MV, Bonfá E, Borba EF, Takiuti AD, Silva CA. Menstrual and hormonal alterations in juvenile systemic lupus erythematosus. Lupus 2009; 18: 38-43.

40. Aikawa NE, Sallum AM, Leal MM, Bonfá E, Pereira RM, Silva CA. Menstrual and hormonal alterations in juvenile dermatomyositis. Clin Exp Rheumatol 2010; 28: 571-575. 
7 APÊNDICES

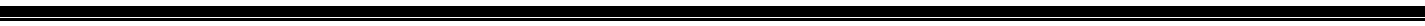




\section{APÊNDICE 1}

Artigo "Primary antiphospholipid syndrome: morphofunctional penile abnormalities with normal sperm analysis"

Publicado online em 17 de outubro de 2011 na Revista Lupus 


\section{Lupus}

http://lup.sagepub.com/

Primary antiphospholipid syndrome: morphofunctional penile abnormalities with normal sperm analysis

C N Rabelo-Júnior, J Freire de Carvalho, A L Gallinaro, E Bonfá, M Cocuzza, O Saito and C A Silva Lupus published online 17 October 2011 DOI: 10.1177/0961203311422715

The online version of this article can be found at: http://lup.sagepub.com/content/early/2011/10/14/0961203311422715

\section{Published by:}

\$SAGE

http://www.sagepublications.com

Additional services and information for Lupus can be found at:

Email Alerts: http://lup.sagepub.com/cgi/alerts

Subscriptions: http://lup.sagepub.com/subscriptions

Reprints: http://www.sagepub.com/journalsReprints.nav

Permissions: http://www.sagepub.com/journalsPermissions.nav

> Proof - Oct 17, 2011

What is This? 


\title{
PAPER
}

\section{Primary antiphospholipid syndrome: morphofunctional penile abnormalities with normal sperm analysis}

\author{
CN Rabelo-Júnior ${ }^{1}$, J Freire de Carvalho ${ }^{1}$, A Lopes Gallinaro', E Bonfá ${ }^{1}$, M Cocuzza ${ }^{2}$, O Saito ${ }^{3}$ and CA Silva ${ }^{1,4}$ \\ 'Division of Rheumatology, Faculdade de Medicina da Universidade de São Paulo, Brazil; ${ }^{2}$ Department of Urology, Faculdade de Medicina da \\ Universidade de São Paulo, Brazil ${ }^{3}$ Department of Radiology, Faculdade de Medicina da Universidade de São Paulo, Brazil; and ${ }^{4}$ Pediatric \\ Rheumatology Unit, Faculdade de Medicina da Universidade de São Paulo, Brazil
}

\begin{abstract}
Objective: To perform a global gonadal and sexual functions assessment in primary antiphospholipid syndrome (PAPS) patients. Methods: A cross-sectional study was conducted in 12 male PAPS patients and 20 healthy controls. They were assessed by demographic data, clinical features, systematic urological examination, sexual function, testicular ultrasound, seminal parameters according to the World Health Organization (WHO), seminal sperm antibodies, and hormone profile, including follicle stimulating hormone (FSH), luteinizing hormone (LH), morning total testosterone, and thyroid hormones. Results: The median of current age and age of spermarche were similar in PAPS patients and controls ( 37.5 vs. 32.4 years, $p=0.270$, and 13.1 vs. 12.85 years, $p=0.224$, respectively), with a higher frequency of erectile dysfunction in the former group $(25 \%$ vs. $0 \%, p=0.044)$. Further analysis of PAPS patients with and without previous arterial thrombosis demonstrated that the median penis circumference was significantly lower in PAPS with arterial thrombosis than in PAPS without this complication $(8.1[6-10]$ vs. $10.2[10-11] \mathrm{cm}, p=0.007)$. In addition, the median penis circumference was significantly lower in PAPS patients with erectile dysfunction than in patients without this complication $(7.5[6-9.5]$ vs. $9.5[7.5-11] \mathrm{cm}, p=0.039)$. Regarding seminal analysis, the median sperm concentration, sperm motility, and normal sperm forms by WHO guidelines were comparable in PAPS patients and controls $(141.5[33-575]$ vs. $120.06[34.5-$ $329] \times 10^{6} / \mathrm{ml}, p=0.65 ; 61.29[25-80]$ vs. $65.42[43-82] \%, p=0.4 ; 21.12[10-42.5]$ vs. $23.95[10-$ $45] \%, p=0.45$, respectively), and none of them had oligo/azoospermia. No differences were observed between PAPS patients and controls regarding the frequency of antisperm antibodies, testicular volume by ultrasound, or hormone profile (FSH, LH, morning total testosterone, and thyroid hormone) $(p>0.05)$. Conclusions: Normal testicular function has been identified in PAPS patients, in spite of morphofunctional penile abnormalities. Previous arterial thrombosis may underlie penile anthropometry alteration. Lupus (2011) 0, 1-6.
\end{abstract}

Key words: antiphospholipid syndrome; antisperm antibodies; fertility; penile; rheumatic disease; sperm

\section{Introduction}

Antiphospholipid syndrome (APS) is an autoimmune thrombophilic condition ${ }^{1}$ that can occur with another autoimmune disease, most often systemic lupus erythematosus (SLE-APS), ${ }^{2,3}$ or in the isolated form - primary APS (PAPS). About $8 \%$ to $18 \%$ of affected patients are male and most organ

Correspondence to: Clovis Artur Almeida Silva, Disciplina de Reumatologia, Faculdade de Medicina da Universidade de São Paulo, Av. Dr Arnaldo 455, sala 3133, CEP 01246-903, São Paulo, SP, Brazil

Email: clovis.silva@icr.usp.br

Received 22 June 2011; accepted 11 August 2011

(c) The Author(s), 2011. Reprints and permissions: http://www. sagepub.co.ukjiourmalsPermissions.na systems in the human body, including testicles, ${ }^{4}$ may be affected.

Testicular evaluation in autoimmune rheumatic disease requires a complete urological examination in order to assess sperm abnormalities due to aging, ${ }^{5,6}$ genital abnormalities, ${ }^{7}$ hypothalamicpituitary-axis dysfunction, antisperm antibodies ${ }^{8}$ and effects of drug treatment, particularly immunosuppressive agents. ${ }^{9-15}$

We have previously reported severe sperm abnormalities associated with cyclophosphamide treatment in male SLE patients ${ }^{12,13}$ and reduced penile dimensions not associated with erectile dysfunction in pre-pubertal SLE without APS. ${ }^{16}$ Of note, testicular thrombosis due to PAPS and SLE-APS has been described in a few case reports

$10.1177 / 0961203311422715$ 
in the literature..$^{3,17-21}$ There is, however, no systematic study assessing the overall gonadal function in PAPS patients with these conditions.

Therefore, the aim of this study was to perform global testicular and sexual function assessments in male patients with PAPS, evaluating its possible association with clinical and laboratory parameters.

\section{Patients and methods}

\section{PAPS patients and controls}

We initially screened 38 male patients with APS without a medical history of hydrocele, hypospadias, cryptorchidism, testicular infection, testicular cancer, orchitis, testicular vasculitis, urethral impairment, previous history of any scrotal or inguinal surgery, diabetes mellitus, or tobacco use. None of the participants had a history of alcohol consumption or heavy occasional drinking before or at study entry. Of the 38 patients, 26 patients were excluded due to previous vasectomy $(n=3)$, refusal to collect sperm sample $(n=9)$, or association with other rheumatic diseases $(n=14)$ (systemic lupus erythematosus, $n=10$; polyarteritis nodosa, $n=2$; rheumatoid arthritis, $n=1$; and ankylosing spondylitis, $n=1$ ). Therefore, a crosssectional study was conducted in 12 PAPS patients regularly followed at the Antiphospholipid Outpatient Clinic of the Rheumatology Division of Hospital das Clínicas da Faculdade de Medicina da Universidade de São Paulo from May 2008 to February 2011. All patients fulfilled the Sapporo criteria for APS diagnosis. ${ }^{22}$ The control group included 20 healthy subjects followed at the Pre-vasectomy Group of the Urology Division of our University Hospital. All PAPS patients and controls were at Tanner stage $5 .^{23}$ The Local Ethics Committee approved this study and informed consent was obtained from all participants.

\section{Global reproductive health evaluation}

Demographic data and body mass index

Current age, age at spermarche (first ejaculation), and race were recorded in PAPS patients and controls, and age at disease onset and disease duration in PAPS patients. Body mass index (BMI) was defined by the formula BMI $\left(\mathrm{kg} / \mathrm{m}^{2}\right)$.

Urologic evaluation and sexual function

A clinical assessment of the genitalia included evaluation of testicles, epididymis, vas deferens, scrotum and penis. Penis length was measured as linear distance along the dorsal side of the penis extending from the pubopenile skin junction to the tip of the glans in the flaccid state, while penis circumference was measured at the middle of the shaft. ${ }^{24}$ Sexual function in patients and controls was evaluated by the male sexual quotient, an self-administered questionnaire validated in Brazilian Portuguese. ${ }^{25}$

Testicular Doppler ultrasound

Ultrasound was performed blinded to the results of the semen analysis in PAPS patients and controls. The largest measurement in each dimension was recorded and used to calculate the testicular volume according to the formula for an ellipsoid (length $\times$ width $\times$ thickness $\times 0.52$ ). The normal mean $\pm \mathrm{SD}$ value in male post-pubertal adolescents and adults is $7-23 \mathrm{ml} .^{11-13,26}$

\section{Hormone evaluation}

Hormone determinations performed at study entry in PAPS patients and controls included: follicle-stimulating hormone (FSH), luteinizing hormone (LH), morning total testosterone, triiodothyronine (T3), tetraiodothyronine (T4), free tetraiodothyronine (free T4), and thyrotropin (TSH) detected by flioroimmunoassay using DELFIA time-resolved fluoroimmunoassay kits (Wallac, Turku, Finland). Intra- and inter-assay coefficients of variation were limited to $3.5 \%$ and $2.1 \%$, respectively. The normal ranges were: FSH (1-10.5 IU/1), LH (1-8.4 IU/1), total morning testosterone $(271-965 \mathrm{ng} / \mathrm{dl}), \mathrm{T} 3$ $(70-200 \mathrm{ng} / \mathrm{dl})$, T4 $(4.5-12 \mu \mathrm{g} / \mathrm{dl})$, free T4 $(0.7-$ $1.5 \mathrm{ng} / \mathrm{dl})$, and TSH $(0.4-4.5 \mu \mathrm{U} / \mathrm{ml})$.

\section{Sperm evaluation}

Sperm analysis was performed according to the guidelines of the World Health Organization (WHO) ${ }^{7}$ by two expert medical technologists. All PAPS patients and controls collected two semen samples at an interval of 15-30 days after 48-72 h of sexual abstinence. The spermatozoa were analyzed by manual hand count as well as by a computer-assisted semen analysis system under $400 \times$ magnification, using an HTM-2030 (Hamilton Thorne Research, Beverly, MA, USA). Sperm morphology included evaluation of sperm head, neck, midpiece, and tail by WHO guidelines and Kruger strict criteria. ${ }^{27}$ Azoospermia was defined as no spermatozoa in the ejaculate and oligozoospermia as sperm concentration $<20 \mathrm{million} / \mathrm{ml}$. $^{9}$ The presence of antisperm antibodies was determined by direct Immunobead test using Immunobead ${ }^{\mathrm{R}}$ rabbit antihuman $\operatorname{Ig}(\operatorname{IgA}, \operatorname{IgG}$, and $\operatorname{IgM}$ ) kits (Irvine Scientific, 
Santa Ana, CA, USA) in all patients and controls. At least $50 \%$ of the motile spermatozoa ('a' + 'b') must be coated with Immunobeads before the test results are considered to be clinically significant. A negative control should have a score of $<10 \%$ bead attachment, and a positive control should have a score of $>20 \%$ bead attachment.?

Clinical evaluation

The following clinical parameters were evaluated in PAPS patients: venous thrombosis (documented deep vein thrombosis and/or pulmonary embolism), arterial thrombosis (clinically documented stroke, transient ischemic attacks or acute myocardial infarction), livedo reticularis and thrombocytopenia $\left(<100,000 / \mathrm{mm}^{3}\right.$ platelets, on at least two distinct occasions)

Serum immunologic analysis

Anticardiolipin antibodies were detected by a commercial kit (Enzyme Immunoassay Kit, BINDAZYME $^{\mathrm{TM}}$, Birmingham, UK) in all APS patients. The cutoff values were: $<11$ GPL/MPL (units) $\mathrm{U} / \mathrm{ml}$ negative, $\geq 11$ and $<20 \mathrm{GPL} / \mathrm{MPL}$ $\mathrm{U} / \mathrm{ml}$ indeterminate, and $\geq 20$ positive. ${ }^{28}$ Lupus anticoagulant (LAC) was detected according to international guidelines. ${ }^{29}$ Serum $\mathrm{IgG}$ and $\mathrm{IgM}$ anti-beta-2-glycoprotein I were detected by enzyme-linked immunoabsorbent assay (ELISA) (ORG 521 Anti-beta-2-Glycoprotein I IgG/IgM Mainz, Germany) with cutoff values of $8 \mathrm{U} / \mathrm{ml}$ for $\operatorname{IgM}$ and $\operatorname{IgG}$, and with intra-assay variation $2.1-5.0 \%$ and inter-assay variation $2.6-7.95 \%$ for $\mathrm{IgG}$ and intra-assay variation $2.1-3.8 \%$ and interassay variation $4.1-6.3 \%$ for $\operatorname{IgM}$.

Statistical analysis

Data were compared by $t$-test or MannWhitney test if numerical data presented a normal or non-normal distribution, respectively, to evaluate differences between PAPS patients and controls according to previous arterial thrombosis and erectile dysfunction. For categorical variables, differences were assessed by Fisher's exact test. $p$ values less than 0.05 were considered significant.

\section{Results}

\section{PAPS patients versus controls}

The demographic data, BMI, penile anthropometry, testicular volume by ultrasound, sperm analysis, antisperm antibodies, and hormone evaluation in PAPS patients and controls are illustrated in
Table 1. The median of current age and age of spermarche were similar in both groups (37.5 [21$62]$ vs. $32.4[18-54]$ years, $p=0.270$, and $13.1[12$ 16] vs. 12.85 [11-15] years, $p=0.224$, respectively), whereas the BMI was significantly higher in PAPS patients (26.06 [15.7-34.6] vs. $22.2[18-27] \mathrm{kg} / \mathrm{m}^{2}$, $p=0.006$ ).

Erectile dysfunction was significantly higher in PAPS patients than in controls $(25 \%$ vs. $0 \%$, $p=0.044$ ) (Table 1). The penis anthropometry, sperm parameters, antisperm antibodies and hormones were similar in PAPS patients and controls $(p>0.05$, Table 1). All PAPS patients and controls had normal thyroid hormones.

\section{PAPS patients}

The subgroup analysis of PAPS patients with $(n=7)$ and without $(n=5)$ previous arterial thrombosis demonstrated that the median penis circumference was significantly lower in PAPS patients with arterial events (8.1 [6-10] vs. 10.2 [10-11] $\mathrm{cm}, p=0.007)$, whereas a similar median penis length was found in both groups $(9.1$ [7-12] vs. 10.9 [9.5-13] cm, $p=0.08)$. Forty-two percent of PAPS patients with previous arterial thrombosis had erectile dysfunction, compared with no patients without arterial events $(p=0.204)$ (Table 2). Further analysis revealed that the median penis circumference was significantly lower in PAPS patients with $(n=3)$ erectile dysfunction vs. without $(n=9)$ this complication (7.5 [6-9.5] vs. 9.5 [7.5-11] cm, $p=0.039)$. No differences were evidenced in the median penis length between groups (8.33 [7-11.5] vs. 10.22 [8-13] $\mathrm{cm}, p=0.280)$.

The demographic data, BMI, testicular volume by ultrasound, hormonal profile, sperm analysis, and clinic and laboratory features were similar in PAPS patients with and without previous arterial events ( $p>0.05$; Table 2).

\section{Discussion}

To our knowledge, this was the first study that specifically addressed gonadal and sexual function in PAPS patients, identifying a reduced penile size associated with previous arterial thrombosis.

The limited number of patients and the crosssectional design are the drawbacks of this study. However, strengths of the study are that the data were collected prospectively and all patients received a close and pre-established protocol. Systematic penile and testicular evaluations were performed using established criteria for penis 
Table 1 Demographic data and body mass index (BMI), penis anthropometry, testicular volume by ultrasound, sperm analysis, antisperm antibodies, and hormone evaluation in primary antiphospholipid syndrome (PAPS) patients and healthy controls

\begin{tabular}{|c|c|c|c|}
\hline Variables & $P A P S(\mathrm{n}=12)$ & Controls $(\mathrm{n}=20)$ & $\mathrm{p}$ \\
\hline \multicolumn{4}{|l|}{ Demographic data and BMI } \\
\hline Current age, years & $37.5(21-62)$ & $32.4(18-54)$ & 0.270 \\
\hline Age at disease onset, years & $31.41(18-61)$ & & \\
\hline Disease duration, years & $6.08(1-18)$ & & \\
\hline Age at spermarche, years & $13.1(12-16)$ & $12.85(11-15)$ & 0.224 \\
\hline Caucasian race & $6(50)$ & $7(33)$ & 0.473 \\
\hline BMI, $\mathrm{kg} / \mathrm{m}^{2}$ & $26.06(15.7-34.6)$ & $22.2(18-27)$ & 0.006 \\
\hline \multicolumn{4}{|l|}{ Penis anthropometry and erectile dysfunction } \\
\hline Length, $\mathrm{cm}$ & $9.87(7-13)$ & $10.02(8-13)$ & 0.358 \\
\hline Circumference, $\mathrm{cm}$ & $9(6-11)$ & $9.42(7-11)$ & 0.185 \\
\hline Erectile dysfunction & $3(25)$ & 0 & 0.044 \\
\hline \multicolumn{4}{|l|}{ Testicular volume } \\
\hline Right, ml & $12.85(7.2-18.4)$ & $13.41(8.5-20.6)$ & 0.68 \\
\hline Left, ml & $13.88(7.7-20)$ & $12.85(6-21.2)$ & 0.22 \\
\hline \multicolumn{4}{|l|}{ Sperm analysis } \\
\hline Sperm volume, $\mathrm{ml}$ & $3.1 \pm 1.41$ & $1.66 \pm 1.28$ & 0.25 \\
\hline Sperm concentration, $\times 10^{6} / \mathrm{ml}$ & $141.5(33-575)$ & $120.06(34.5-329)$ & 0.65 \\
\hline Oligo/azoospermia & 0 & 0 & 1.0 \\
\hline Total sperm count, $\times 10^{6}$ & $388(66-1131)$ & $300.5(41.3-1176)$ & 0.4 \\
\hline Sperm motility, $\%$ & $61.29(25-80)$ & $65.42(43-82)$ & 0.4 \\
\hline Normal sperm forms by WHO guidelines, $\%$ & $21.12(10-42.5)$ & $23.95(10-45)$ & 0.45 \\
\hline Normal sperm forms by Kruger, \% & $5.79(1.5-16.5)$ & $7.65(3-18)$ & 0.27 \\
\hline Antisperm antibodies, $\%$ & $21.08(8-60)$ & $16.9(0-32)$ & 0.35 \\
\hline \multicolumn{4}{|l|}{ Hormone evaluation } \\
\hline FSH, IU/liter & $5.06(1-26.8)$ & $3.32(1-5.9)$ & 0.207 \\
\hline Elevated levels & $1(8)$ & 0 & 0.375 \\
\hline LH, IU/liter & $4.48(1-13.1)$ & $3.49(1.8-5.8)$ & 0.171 \\
\hline Elevated levels & $1(8)$ & 0 & 0.375 \\
\hline Morning total testosterone, $\mathrm{ng} / \mathrm{dl}$ & $533(309-803)$ & $552.5(230-1078)$ & 0.381 \\
\hline Lower levels & 0 & $1(5)$ & 1.0 \\
\hline
\end{tabular}

Values expressed in mean $\pm \mathrm{SD}$, median (range) or $n(\%)$

FSH: follicle-stimulating hormone, LH: luteinizing hormone, WHO: World Health Organization. Reference values: FSH 1-10.5 IU/liter, LH 1-8.4 IU/liter, Morning total testosterone 271-965-ng/dl. The values in bold: $\mathrm{p}<0.05$ (statistically significant).

anthropometry, ${ }^{16,24}$ sperm and antisperm antibody assessments, ${ }^{5,6}$ and the inclusion of only post-pubertal subjects. In addition, the restricted selection criteria of PAPS patients and controls without a medical history of testicular abnormalities and comorbidities is relevant, since these conditions may affect gonadal evaluation. ${ }^{6}$

Development of penis dimensions occurs only during puberty and may be influenced by genetic background, hypothalamic-pituitary-axis dysfunction and chronic diseases, as described in our SLE patients. ${ }^{5,16}$ Androgens produced by testis and adrenal glands at pubertal age are probably the most important factor in the development of the genital organs, including the penis. ${ }^{30}$ All of our PAPS patients with reduction of penile anthropometry had disease onset after spermarche, indicating that their reduced penis dimension was not attributed to pubertal development during adolescence.

Interestingly, PAPS patients with previous arterial events had reduced penile circumference, raising the possibility that chronic subclinical endothelial dysfunction involving corpus cavernosum may result in atrophy. ${ }^{31} \mathrm{We}$ are currently performing Doppler evaluation to test this hypothesis. Of note, the entire group of patients was asymptomatic, without a history of penis edema or pain. To our knowledge there are no cases of clinical penis thrombosis in PAPS patients reported in the literature.

Remarkably, erectile dysfunction occurred particularly in PAPS patients with reduced penile circumference. This sexual dysfunction is characterized by the inability of a man to achieve an erection and maintain it sufficiently for sexual performance. ${ }^{32}$ Sexual impotence was also recently reported by our group in a small population with APS linked to arterial events, ${ }^{33}$ suggesting that erectile dysfunction may be linked to local subclinical endothelial cell dysfunction in PAPS patients.

The penis morphofunctional abnormalities in PAPS patients described herein are of major 
Table 2 Demographic data, body mass index (BMI), penis anthropometry, testicular volume by ultrasound, sperm analysis, antisperm antibodies, hormone evaluation, and clinical and laboratory features at study entry in primary antiphospholipid syndrome (PAPS) patients with and without previous arterial events

\begin{tabular}{|c|c|c|c|}
\hline Variables & PAPS with arterial events $(\mathrm{n}=7)$ & PAPS without arterial events $(\mathrm{n}=5)$ & $\mathrm{p}$ \\
\hline \multicolumn{4}{|l|}{ Demographic data and BMI } \\
\hline Current age, years & $40.7(24-62)$ & $33(21-53)$ & 0.334 \\
\hline Disease duration, years & $6.1(1-16)$ & $6(2-18)$ & 0.969 \\
\hline Age of spermarche, years & $13.5(12-16)$ & $12.6(12-13)$ & 0.1 \\
\hline Caucasian race & $3(42)$ & $1(20)$ & 0.417 \\
\hline BMI. $\mathrm{kg} / \mathrm{m}^{2}$ & $27.2(24-34.6)$ & $24.4(15.7-27.7)$ & 0.27 \\
\hline \multicolumn{4}{|l|}{ Penis anthropometry and erectile dysfunction } \\
\hline Length. $\mathrm{cm}$ & $9.1(7-12)$ & $10.9(9.5-13)$ & 0.08 \\
\hline Circumference, $\mathrm{cm}$ & $8.1(6-10)$ & $10.2(10-11)$ & 0.007 \\
\hline Erectile dysfunction & $3(42)$ & 0 & 0.204 \\
\hline \multicolumn{4}{|l|}{ Testicular volume } \\
\hline Right, ml & $12.5(7.2-17)$ & $13.3(8.2-18.4)$ & 0.738 \\
\hline Left, ml & $13.7(7.7-20)$ & $14(12-17)$ & 0.902 \\
\hline \multicolumn{4}{|l|}{ Sperm analysis } \\
\hline Sperm volume, $\mathrm{ml}$ & $3.1(1.5-6.8)$ & $3.1(2.5-3.5)$ & 0.985 \\
\hline Sperm concentration, $\times 10^{6} / \mathrm{ml}$ & $156(33-575)$ & $121.1(55-255)$ & 0.674 \\
\hline Total sperm count, $\times 10^{6}$ & $416(66-1131)$ & $348.8(165-637)$ & 0.74 \\
\hline Sperm motility, $\%$ & $58.2(25-65)$ & $65.6(40-80)$ & 0.419 \\
\hline Normal sperm forms by WHO guidelines, $\%$ & $21.2(10-42.5)$ & $20.9(13.5-33)$ & 0.95 \\
\hline Normal sperm forms by Kruger, $\%$ & $6.28(1.5-16.5)$ & $5.1(1.5-10)$ & 0.655 \\
\hline Antisperm antibodies, $\%$ & $25.7(8-60)$ & $14.6(11-17)$ & 0.164 \\
\hline \multicolumn{4}{|l|}{ Hormone evaluation } \\
\hline FSH, IU/1 & $6.24(0.8-26.8)$ & $3.38(1.3-5.3)$ & 0.451 \\
\hline Elevated levels & $1(14)$ & $3(60)$ & 0.222 \\
\hline LH, IU/1 & $4.65(1-13.1)$ & $4.24(2.6-8)$ & 0.82 \\
\hline Elevated levels & $1(14)$ & 0 & 1.0 \\
\hline Morning total testosterone, $\mathrm{ng} / \mathrm{dl}$ & $522.4(417--622)$ & $547.8(309-803)$ & 0.78 \\
\hline Lower levels & 0 & 0 & 1.0 \\
\hline \multicolumn{4}{|l|}{ Clinical and laboratory features, $\%$} \\
\hline Thrombocytopenia & 0 & 0 & 1.0 \\
\hline Livedo reticularis & 0 & 0 & 1.0 \\
\hline IgM anticardiolipin, $>20 \mathrm{MPL}$ & $2(28)$ & $1(20)$ & 1.0 \\
\hline IgG anticardiolipin, $>20 \mathrm{GPL}$ & $1(14)$ & $1(20)$ & 1.0 \\
\hline Lupus anticoagulant & $3(42)$ & $5(100)$ & 0.08 \\
\hline IgM anti-beta2-glycoprotein $\mathrm{I},>8 \mathrm{U} / \mathrm{ml}$ & $2(28)$ & $1(20)$ & 1.0 \\
\hline IgG anti-beta2-glycoprotein $1,>8 \mathrm{U} / \mathrm{ml}$ & $3(42)$ & $1(20)$ & 0.575 \\
\hline
\end{tabular}

Values expressed as median (range) or $n(\%)$.

BMI: body mass index, FSH: follicle-stimulating hormone, LH: luteinizing hormone, PAPS: primary antiphospholipid syndrome, WHO: World Health Organization.

Reference values: FSH 1-10.5 IU/liter, LH 1-8.4 IU/liter, Morning total testosterone 271-965--ng/dl.

The values in bold: $p<0.05$ (statistically significant).

concern, since they contribute to psychological distress, with a consequent reduction of health-related quality of life. ${ }^{32}$ In spite of this, our extensive evaluation revealed that PAPS patients have normal testicular function, a reassuring fertility preservation. In fact, testicular thrombosis was rarely reported in these patients. ${ }^{4}$ Moreover, only men with a flaccid length of less than $4 \mathrm{~cm}$ should be considered candidates for penile enlargement, and none of our PAPS patients had micropenis. ${ }^{34}$

In conclusion, we have identified normal testicular function, in spite of morphofunctional penile abnormalities. Previous arterial thrombosis may underlie penile anthropometry alteration.

\section{Conflict of interest}

None declared.

\section{Funding}

This study was supported by Fundação de Amparo à Pesquisa do Estado de São Paulo - FAPESP (grants 2004/07832-2 and 2005/56482-7 to CAS) and Conselho Nacional de Desenvolvimento Científico e Tecnológico - CNPQ (grants 3300665/2009-1 to JFC, 301411/2009-3 to EB, and 


\section{APÊNDICE 2}

Artigo "Moderate/severe erectile dysfunction in patients with antiphospholipid syndrome"

Publicado online em 10 de novembro de 2011 na Revista Lupus 
300248/2008-3 to CAS) and Federico Foundation Grants to JFC, EB, and CAS.

\section{Acknowledgements}

Our gratitude to Prof. Carmita Abdo for support in sexual function, Maribê Salan Marcos and Rosa Casemiro for technical support, and Francisco Erivelton Aragão for the statistical analysis.

\section{References}

1 de Groot PG, Derksen RH, de Laat B. Twenty-two years of failure to set up undisputed assays to detect patients with the antipho: spholipid syndrome. Semin Thromb Hemost 2008; 34: 347-355.

2 Cervera R, Khamashta MA, Shoenfeld Y, et al. Morbidity and mortality in the antiphospholipid syndrome during a 5-year period: a multicentre prospective study of 1000 patients. Ann Rheum Dis 2009; 68: 1428-1432.

3 Mejia-Romero R, García-Carrasco M, Galarza-Maldonado C, et al. Primary antiphospholipid syndrome in Latin American mestizo patients: clinical and immunologic characteristics and comparison with European patients. Clin Rheumatol 2008; 27: 891-897.

4 Mehdi AA, Salti I, Uthman I. Antiphospholipid syndrome: endocrinologic manifestations and organ involvement. Semin Thromb Hemost 2011; 37: 49-57.

5 Silva CA, Brunner HI. Gonadal functioning and preservation of reproductive fitness with juvenile systemic lupus erythematosus. Lupus 2007; 16: 593-599.

6 Silva CA, Bonfa E, Ostensen M. Maintenance of fertility in patients with rheumatic diseases needing anti-inflammatory and immunosuppressive drugs. Arthritis Care Res (Hoboken) 2010; 62: 1682-1690.

7 Rowe PJ, Comhaire FH, Hargreave TB, Mahmoud AM. World Health Organization (WHO) manual for the standardized investigation, diagnosis and management of the infertile male, 1st ed. Cambridge: Cambridge University Press; 2000. p. 1-86.

8 Shefi S, Turek PJ. Definition and current evaluation of subfertile men. Int Braz J Urol 2006; 32: 385-397.

9 Østensen M, Lockshin M, Doria A, et al. Update on safety during pregnancy of biological agents and some immunosuppressive antirheumatic drugs. Rheumatology (Oxford) 2008; 47: 28-31.

10 Ostensen M, Brucato A, Carp H, et al. Pregnancy and reproduction in autoimmune rheumatic diseases. Rheumatology (Oxford) 2011; 50: 657-664.

11 Silva CA, Hallak J, Pasqualotto FF, Barba MF, Salto MI, Kiss $\mathrm{MH}$. Gonadal function in adolescents and young men with systemic lupus erythematosus. $J$ Rheumatol 2002; 29: 2000-2005.

12 Soares PM, Borba EF, Bonfa E, Hallak J, Corrêa AL, Silva CA Gonad evaluation in male systemic lupus erythematosus. Arthritis Rheum 2007; 56: 2352-2361.

13 Suehiro RM, Borba EF, Bonfa E, et al. Testicular Sertoli cell function in male systemic lupus erythematosus. Rheumatology (Oxford) 2008; 47: 1692-1697
14 Moraes AJ, Pereira RM. Cocuzza M, Casemiro R, Saito O, Silva CA. Minor sperm abnormalities in young male post-pubertal patients with juvenile dermatomyositis. Braz J Med Biol Res 2008: 41: 1142-1147.

15 Moraes AJ, Pereira RM, Cocuzza M, Casemiro R, Saito O, Silva CA. Gonad evaluation in male dermatomyositis. A pilot study. Clin Exp Rheumatol 2010; 28: 441-442.

16 Vecchi A, Borba E, Bonfá E, et al. Penile anthropometry in systemic lupus erythematosus patients. Lupus 2011; 20: 512-518.

17 Wu VH, Dangman BC, Kaufman Jr RP. Sonographic appearance of acute testicular venous infarction in a patient with a hypercoagulable state. J Ultrasound Med 1995; 14: 57-59.

18 Leder AN, Flansbaum B. Zandman-Goddard G, Asherson R, Shoenfeld Y. Antiphospholipid syndrome induced by HIV. Lupus 2001; 10: 370-374.

19 Göbel U, Kettritz R, Schneider W, Luft FC. A particularly private pain. Nephrol Dial Transplant 2002; 17: 516-518.

20 Fernández Rosado E, Sánchez Rodríguez-Losada J, Alvarez Castelo L, et al. Urologic damage of the primary antiphospholipid syndrome. Arch Esp Urol 2004; 57: 707-723.

21 Uthman I, Salti I, Khamashta M. Endocrinologic manifestations of the antiphospholipid syndrome. Lupus 2006; 15: 485-489.

22 Wilson WA, Gharavi AE, Koike T, et al. International consensus statement on preliminary classification criteria for definite antiphospholipid syndrome: report of an international workshop. Arthritis Rheum 1999; 42: 1309-1311.

23 Tanner JM. Growth at adolescence, 2nd ed. Oxford: Blackwell Scientific Publications; 1962.

24 Ponchietti R, Mondaini N, Bonafè M, Di Loro F, Biscioni S, Masieri L. Penile length and circumference: a study on 3,300 young Italian males. Eur Urol 2001; 39: 183-186.

25 Abdo CH. The male sexual quotient: a brief, self-administered questionnaire to assess male sexual satisfaction. $J$ Sex Med 2007; 4: $382-389$.

26 Atkinson GO, Patrick LE, Ball TI. The normal and abnormal scrotum in children: evaluation with color Doppler sonography. Am J Roentgenol 1992; 158: 613-617.

27 Kruger TF, Acosta AA, Simmons KF, Swanson RJ, Matta JF, Oehninger S. Predictive value of abnormal sperm morphology in in vitro fertilization. Fertil Steril 1988; 49: 112-117.

28 Haris EN, Pierangeli S, Birch D. Cardiolipin Wet Workshop report. Am J Clin Path 1994; 101: 616-624.

29 Wisloff F, Jacobsen EM, Liestol S. Laboratory diagnosis of the antiphospholipid syndrome. Thromb Res 2002; 108: 263-271.

30 Dohle GR, Smit M, Weber RF. Androgens and male fertility. World J Urol 2003; 21: 341-345.

31 El-Sakka AI, Yassin AA. Amelioration of penile fibrosis: myth or reality. J Androl 2010; 31: 324-335.

32 Araujo DB, Borba EF, Abdo CH, et al. Sexual function in rheumatic diseases. Acta Reumatol Port 2010; 35: 16-23.

33 Gallinaro AL, Silva CA, Rabelo-Junior CN, Caleiro MT, Carvalho JF. Moderate/severe erectile dysfunction in patients with antiphospholipid (Hughes') syndrome. Lupus 2011; (submitted).

34 Wessells H, Lue TF, McAninch JW. Penile length in the flaccid and erect states: guidelines for penile augmentation. J Urol 1996; 156: 995-997. 


\section{Lupus}

http://lup.sagepub.com/

\section{Moderate/severe erectile dysfunction in patients with antiphospholipid syndrome}

A Lopes Gallinaro, CA Silva, C N Rabelo Junior, M T Caleiro and J F de Carvalho

Lupus published online 10 November 2011

DOI: $10.1177 / 0961203311427552$

The online version of this article can be found at:

http://lup.sagepub.com/content/early/2011/11/10/0961203311427552

\section{Published by:}

(\$)SAGE

http://www.sagepublications.com

Additional services and information for Lupus can be found at:

Email Alerts: http://lup.sagepub.com/cgi/alerts

Subscriptions: http://lup.sagepub.com/subscriptions

Reprints: http://www.sagepub.com/journalsReprints.nav

Permissions: http://www.sagepub.com/journalsPermissions.nav

> Proof - Nov 10, 2011

What is This? 


\title{
CONCISE REPORT
}

\section{Moderate/severe erectile dysfunction in patients with antiphospholipid syndrome}

\author{
A Lopes Gallinaro ${ }^{1}, \mathrm{CA} \mathrm{Silva}^{2}$, CN Rabelo Junior ${ }^{2}$, MT Correia Caleiro' ${ }^{1}$ and JF de Carvalho' \\ ${ }^{1}$ Rheumatology Division, Hospital das Clínicas da Faculdade de Medicina da Universidade de São Paulo, Brazil; ${ }^{2}$ Pediatric Rheumatology Unit, \\ Hospital das Clínicas da Faculdade de Medicina da Universidade de São Paulo, Brazil
}

\begin{abstract}
Purpose: To evaluate sexual function of antiphospholipid syndrome (APS) patients using the Brazilian version of the validated International Index of Erectile Function (IIEF).

Materials and methods: Eleven APS male patients (Sapporo criteria) were age and racematched with 22 healthy controls. Demographic and clinical data, drug use and antiphospholipid antibodies were evaluated. The IIEF was also self-applied.

Results: Mean age $(p=0.114)$, frequency of Caucasian race $(p=1.00)$ and married status $(p=0.438)$ were similar in APS and controls. Mean disease duration was $8.8 \pm 4.6$ years. Erectile dysfunction (ED) was frequently observed in APS versus controls (45.5 vs. $4.5 \%, p=0.0096)$, especially moderate/severe ED $(p=0.0081)$. The total IIEF score $(49.6$ vs. $67.1, p=0.019$ ), erectile function (19.6 vs. $28.1, p=0.005$ ) and intercourse satisfaction ( 7.8 vs. $11.9, p=0.009)$ were lower in patients than in controls. No differences were seen in orgasmic function $(p=0.114)$, sexual desire $(p=0.123)$ or overall satisfaction $(p=0.097)$ between the groups. The comparison between APS patients with ED $(n=5)$ and without $\operatorname{ED}(n=6)$ revealed more arterial events in APS with ED (100 vs. $16.7 \%, p=0.0152)$, and also longer disease duration $(12[7-16]$ vs. $5.5[2-13]$ years, $p=0.031)$. A trend towards lower venous events ( 20 vs. $83.3 \%, p=0.0801)$ and higher renal thrombotic microangiopathy $(60 \%$ vs. $0, p=0.0606$ ) was observed in APS patients with ED. Demographics, clinical manifestations, smoking and antiphospholipid antibodies positivity were similar in both groups.

Conclusion: To our knowledge, this was the first study that demonstrated moderate/severe ED in almost $50 \%$ of cases of a rare autoimmune disease. This alteration was linked to arterial events and longer disease duration. Lupus (2011) 0, 1-5.
\end{abstract}

Key words: antiphospholipid syndrome; erectile dysfunction; impotence; International Index of Erectile Function (IIEF) Brazilian version

\section{Introduction}

Sexual dysfunction in men with rheumatic diseases has been reported. ${ }^{1}$ In respect of antiphospholipid syndrome (APS), a rare rheumatic disease that is characterized by vascular events, it is logical to speculate that the impairment of the penile vascular system could result in symptoms of erectile dysfunction (ED). However, no studies have evaluated erectile function in subjects with this thrombophilia.

Correspondence to: J Freire de Carvalho, Disciplina de Reumatologia Faculdade de Medicina da Universidade de São Paulo- Av. Dr. Arnaldo, $4553^{\circ}$ andar, Sala 3190 -São Paulo - SP - Brazil- CEP 01246-903

Email: jotafc@gmail.com

Received 28 April 2011; accepted 27 September 2011
The objectives of this study were, therefore, firstly to investigate the presence of ED using a specific questionnaire in patients with APS and compare it with a control population matched for age and race, and secondly to evaluate its possible association with clinical aspects of the disease.

\section{Materials and methods}

We screened 320 patients; 300 were excluded because they were female. Nine out of the remaining 20 were excluded due to not living in a partnership situation $(n=2)$ or use of drugs that could influence sexual function ( $n=7$; sildenafil $[n=1]$, tadalafil $[n=1]$, amlodipine $[n=2]$, captopril $[n=1]$ and losartan $[\mathrm{n}=2])$. For this study, 11 
APS patients aged over 18 were included (Figure 1). All patients fulfilled the international criteria for APS according to the Sapporo criteria ${ }^{2}$ and were followed up at our Outpatient Clinic of the Rheumatology Division, Hospital das Clínicas da Faculdade de Medicina da Universidade de São Paulo (HC-FMUSP). The control group was composed of 22 healthy men, matched for age and race.

The inclusion criteria for APS patients and controls were having a sexual partner and being more than 18 years old. Exclusion criteria were penile impairment, diabetes mellitus, thyroid diseases, previous or current history of alcohol, tobacco use or illicit drugs, and use of any drugs that could induce erectile dysfunction, such as antidepressants, beta-blockers, alpha-blockers, central adrenergic blockers, testosterone, sildenafil, tadalafil and vardenafil.

We collected demographic data and reviewed medical records, characterizing APS and previous events of arterial thrombosis, venous thrombosis, the presence of thrombocytopenia, duration of disease, and presence of cardiovascular and cerebrovascular events (angina, acute infarction and stroke). Prior comorbidities and medication use were also included.

The International Index of Erectile Function (IIEF) is a 15-item questionnaire that was developed in English and validated as an instrument to assess erectile function in the Brazilian Portuguese version that was used in this study. ${ }^{3}$ This instrument examines five domains or dimensions: erectile function (questions 1-5 and question 15), orgasmic function (questions 9 and 10), sexual desire (questions 11 and 12), intercourse satisfaction (questions 6, 7 and 8) and overall satisfaction (questions 13 and 14). Each scale ranges from 0 to 5 , so that the maximum score that can be obtained is 75 . Lower scores indicate poor sexual function.

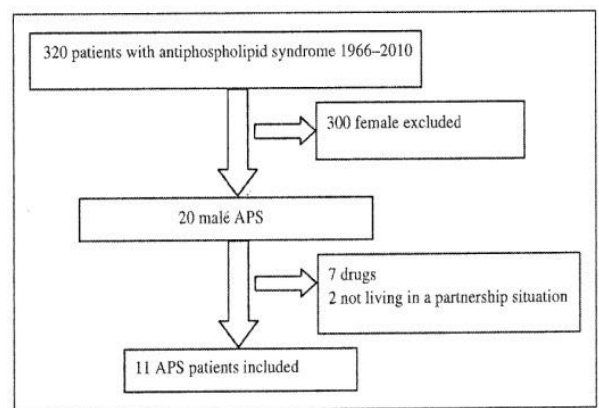

Figure 1 Flow chart of the selection process for identification of male APS patients in our Outpatient Clinic.
An IIEF score greater than 25 is defined as normal erectile function, 21-4 as mild ED, 16-20 as moderate ED and lower than 15 as severe ED. ${ }^{3}$

The Local Ethics Committee approved this study and informed consent was obtained from all participants.

\section{Statistical analysis}

Results are presented as mean \pm standard deviation or median (range) for quantitative variables and frequencies (percentages) for qualitative variables. Statistical analysis was performed using GraphPad software. The Student $t$ or Mann-Whitney test was used to compare means and $\chi^{2}$ or Fisher's exact test for frequencies. $p$ values less than 0.05 were considered significant.

\section{Results}

\section{APS patients versus controls}

Demographic evaluation of APS patients and controls revealed comparable mean age $(46.2 \pm 9.4$ vs. $42.3 \pm 6.0$ years, $p=0.114$ ), frequency of Caucasian race $(81.8 \%$ vs. $81.8 \%, p=1.00)$ and married status $(63.6 \%$ vs. $77.3 \%, p=0.438)$. Nine $(82 \%)$ had primary APS and two had secondary APS. Patients had a mean disease duration of $8.8 \pm 4.6$ years. A lower frequency of occupational activities was observed in APS patients versus controls $(54.5 \%$ vs. $100 \%, p=0.002$ ) and also a higher frequency of physical inactivity $(81.8 \%$ vs. $27.3 \%, p=0.003)$.

ED was observed in APS more frequently than in the control group ( $45.5 \%$ vs. $4.5 \%, p=0.0096)$. Moderate/severe ED was also more evidenced in APS than in controls $(36.4 \%$ vs. $0, p=0.0081)$. The total IIEF score was lower in patients than in controls (49.6 vs. 67.1, $p=0.019$ ), as well as its components, such as erectile function (19.6 vs. 28.1, $p=0.005)$ and intercourse satisfaction (7.8 vs. $11.9, p=0.009)$. No difference was demonstrated in orgasmic function (7.7 vs. 9.6, $p=0.114$ ), sexual desire (7.1 vs. $8.3 ; p=0.123$ ) or overall satisfaction (7.4 vs. 9.1, $p=0.097$ ) between the two groups (Table 1).

\section{APS patients with $E D$ versus those without $E D$}

Arterial events were significantly higher in APS patients with $\operatorname{ED}(n=5)$ than in those without $\mathrm{ED} \quad(n=6) \quad(100 \% \quad$ vs. $16.7 \%, \quad p=0.0152)$. Likewise, the median disease duration was significantly higher in APS patients with ED than in those without this sexual dysfunction (12 [7-16] vs. 5.5 
[2-13] years, $p=0.031)$. A trend towards lower venous events $(20 \%$ vs. $83.3 \%, p=0.0801)$ and higher renal thrombotic microangiopathy $(60 \%$ vs. $0, p=0.0606$ ) was observed in APS patients versus controls. The other demographics, clinical manifestations, smoking and antiphospholipid

Table 1 Erectile dysfunction, severity and its components measured by IIEF of the 11 male APS patients and 22 healthy controls

\begin{tabular}{llll}
\hline & $\begin{array}{l}\text { APS patients } \\
\mathrm{n}=11\end{array}$ & $\begin{array}{l}\text { Controls } \\
\mathrm{n}=22\end{array}$ & $\mathrm{p}$ value \\
\hline Erectile dysfunction, $n(\%)$ & $5(45.5)$ & $1(4.5)$ & $\mathbf{0 . 0 0 9 6}$ \\
$\quad$ Mild & $1(9.1)$ & $1(4.5)$ & 1.0 \\
$\quad$ Moderate or severe & $4(36.4)$ & 0 & $\mathbf{0 . 0 0 8 1}$ \\
Total score of IIEF & $49.55 \pm 22.41$ & $67.14 \pm 5.08$ & $\mathbf{0 . 0 1 9}$ \\
Erectile function & $19.55 \pm 10.36$ & $28.14 \pm 2.05$ & $\mathbf{0 . 0 0 5}$ \\
Orgasmic function & $7.73 \pm 3.50$ & $9.59 \pm 1.18$ & 0.114 \\
Sexual desire & $7.09 \pm 2.17$ & $8.32 \pm 1.49$ & 0.123 \\
Intercourse satisfaction & $7.82 \pm 4.96$ & $11.95 \pm 1.73$ & $\mathbf{0 . 0 0 9}$ \\
Overall satisfaction & $7.36 \pm 2.84$ & $9.14 \pm 1.17$ & 0.097 \\
\hline
\end{tabular}

Data expressed as mean (standard deviation) or percentage. Bold p values are significant. APS: antiphospholipid syndrome, IIEF: International Index of Erectile Function.
Moderate/severe erectile dysfunction in patients with antiphospholipid syndrome A Lopes Gallinaro et al.

antibodies positivity were similar in both groups (Table 2).

\section{Discussion}

To the best of our knowledge, this is the first study to have identified the presence of moderate/severe ED in almost $50 \%$ of APS patients. This alteration was linked to arterial events and longer disease duration.

A great advantage of the present study was the exclusion of secondary causes for sexual dysfunction, such as metabolic conditions. In fact, it is well known that patients with diabetes mellitus often have impotence. ${ }^{4}$ Additionally, it was relevant to exclude subjects who were on drugs that may interfere with sexual function, such as anti-hypertensives, ${ }^{5}$ or medications that improve this function, such as tadalafil and sildenafil. ${ }^{6,7}$ Another benefit was the sole inclusion of patients who fulfilled the international criteria for APS, ${ }^{2}$ forming a homogeneous group for analysis.

In contrast to other studies, ${ }^{8}$ we used a specific and standardized questionnaire to evaluate sexual function. The IIEF instrument is short and easy to

Table 2 Demographic data, clinical and laboratory features, and treatment of the five APS patients with and the six without erectile dysfunction

\begin{tabular}{|c|c|c|c|}
\hline & APS with $E D \mathrm{n}=5$ & APS without $E D \mathrm{n}=6$ & $\mathrm{p}$ value \\
\hline \multicolumn{4}{|l|}{ Demographic data } \\
\hline Current age, years & $52(41-62)$ & $43(27-53)$ & 0.073 \\
\hline Disease duration, years & $12(7-16)$ & $5.5(2-13)$ & 0.0318 \\
\hline Caucasian race, $n(\%)$ & $5(100)$ & $4(66.6)$ & 0.4545 \\
\hline \multicolumn{4}{|l|}{ Clinical and laboratory features, $n(\%)$} \\
\hline Arterial events & $5(100)$ & $1(16.66)$ & 0.0152 \\
\hline Venous events & $1(20)$ & $5(83.33)$ & 0.0801 \\
\hline Livedo reticularis & 0 & $2(33.33)$ & 0.4545 \\
\hline Stroke & $3(60)$ & $1(16.66)$ & 0.2424 \\
\hline Renal thrombotic microangiopathy & $3(60)$ & 0 & 0.0606 \\
\hline Pulmonary thromboembolism & $1(20)$ & $1(16.66)$ & 1.0 \\
\hline Deep venous thrombosis & $1(20)$ & $4(66.66)$ & 0.2424 \\
\hline Dyslipidemia & $1(20)$ & 0 & 0.4545 \\
\hline Previous history of smoking & $1(20)$ & $1(16.66)$ & 1.0 \\
\hline Current smoking & 0 & $3(50)$ & 0.1818 \\
\hline Systemic hypertension & $2(40)$ & $1(16.6)$ & 0.5455 \\
\hline Angina & 0 & 0 & 1.0 \\
\hline \multicolumn{4}{|l|}{ Laboratory features and treatment, $n(\%)$} \\
\hline Thrombocytopenia & 0 & $3(50)$ & 0.1818 \\
\hline Lupus anticoagulant & $4(80)$ & $3(50)$ & 0.5455 \\
\hline IgM anticardiolipin & $1(20)$ & $4(66.66)$ & 0.2424 \\
\hline IgG anticardiolipin & $1(20)$ & $2(33.33)$ & 1.0 \\
\hline Warfarin use & $5(100)$ & $6(100)$ & 1.0 \\
\hline
\end{tabular}

Data expressed as median (range) or percentage. Bold p values are significant. APS: antiphospholipid syndrome, ED: erectile dysfunction. 
administer and understand. It is available in ten languages, including Portuguese, ${ }^{3}$ for use in clinical trials and has shown adequate sensitivity and specificity for detecting disorders related to erectile function in patients with ED. It has some limitations; for instance, it focuses on superficial erectile sexual response and evaluation of the limited partner relationship rather than investigating different aspects of sexual function or evaluating its components. ${ }^{3}$ It was developed with the aim of being a short, reproducible, culturally and psychometrically valid instrument, which can be used by physicians and researchers in clinical and therapeutic trials, as another parameter of evaluation of the efficacy/effectiveness of various interventions proposed today. ${ }^{3}$ Being a self-report, it may encourage imprecision in the results, but preserves intimacy and allows the individual to respond more comfortably to issues considered sensitive, ${ }^{9}$ for which selfreported questionnaires are preferred to interviews. $^{3}$

Sexual dysfunction in men with rheumatic diseases has been reported. ${ }^{1}$ In addition, ED in was found in $12 \%$ of ankylosing spondylitis (AS) patients ${ }^{10}$ and in none of our systemic lupus erythematosus patients without secondary APS. ${ }^{8}$ The IIEF was also applied to men with osteoporosis and $74 \%$ had ED, with scores lower than 22 . The authors found $\mathrm{ED}$ in $41.4 \%$ of individuals aged 50 to 59 years, $30.3 \%$ of subjects aged 60 to 69 years and $16.3 \%$ in those aged 70 years or more. Patients with age greater than 70 years had severe ED, and those between 50 to 59 years had mild ED. ${ }^{11}$ Moreover, a pilot study with AS (age between 29 and 48 years) showed significant improvement in four of the five domains of IIEF after 3 months of using anti-tumor necrosis factor (TNF)- $\alpha$. The improvement in patients with ED was significant in three of five domains (erectile function, sexual satisfaction and sexual desire). ${ }^{12}$

ED in APS patients can be multifactorial, and the factors most associated with ED are age, disease activity and drug use. ${ }^{8}$ It is reasonable to speculate that a thrombotic mechanism may be implicated in the pathophysiology of this ED in APS. In accordance with this, there are some case reports showing thrombosis of penile vessels leading to ED. ${ }^{13}$ On the other hand, endothelial dysfunction represented by atherosclerosis plays a relevant role in ED. In fact, ED has been previously described in diabetic subjects with coronary artery disease. $^{14}$

Interestingly, the ED observed in a large number of APS cases in this study was essentially moderate and severe. This relevant aspect was different in the healthy population; indeed, mild, moderate and severe ED was demonstrated in $30.2 \%, 1.4 \%$ and $0.3 \%$ of the normal subjects, respectively. ${ }^{15}$

In summary, this study suggested that half of APS patients may have moderate/severe ED, evaluated by a specific questionnaire, and low intercourse satisfaction, and that this sexual dysfunction is associated with arterial events and long-term disease. One ongoing study from our group is currently evaluating penile vasculature, and possibly will add new knowledge in this field.

\section{Funding}

This study was supported by Conselho Nacional de Desenvolvimento Científico e Tecnológico - CNPQ (300248/2008-3 to CAS and 300665/2009-1 to JFC) and Federico Foundation to CAS and JFC.

\section{Conflict of interest}

None declared.

\section{References}

1 Araujo DB, Borba EF, Abdo CHN, et al. [Sexual function in rheumatic diseases]. Acta Reumatol Port 2010; 35: 16-23.

2 Lockshin MD, Sammaritano LR, Schwartzman S. Validation of the criteria for antiphospholipid syndrome. Arthritis Rheum 2000; 43: 440-443.

3 Ferraz MB, Cicconelli RM. Translation and cultural adaptation of Erectile Function International Index for postuguese language. Rev Bras Med 1998; 55: 35-40.

4 Meena BL, Kochar DK, Agarwal TD. Association between erectile dysfunction and cardiovascular risk in individuals with type-2 diabetes without overt cardiovascular disease. Int $J$ Diabetes Dev Ctries 2009; 29: 150-154.

5 Papatsoris AG, Korantzopoulos PG. Hypertension, antihypertensive therapy, and erectile dysfunction. Angiology 2006; 57: 47-52.

6 Seftel A, Goldfischer E, Kim ED, Dula E, Zeigler H, Burns P. Onset of efficacy of tadalafil once daily in men with erectile dysfunction: a randomized, double-blind, placebo controlled trial. J Urol 2011; 185: 243-248.

7 Bérnard F, Carrier S, Lee JC, Talwar V, Defoy I. Men with mild erectile dysfunction benefit from sildenafil treatment. $J$ Sex Med 2010; 7: 3725-3735.

8 Vecchi AP, Borba E, Bonfá E, et al. Penile anthropometry in systemic lupus erythematosus patients. Lupus 2011; 20: 512-518.

9 Reis MMF, Abdo CHN. Prevalence of erectile dysfunction as defined by the International Index of Erectile Dysfunction (IIEF) in a sample of Brazilian men who consider themselves healthy. J Sex Marital Ther 2010; 36: 87-100.

10 Pirildar T, Muezzinoglu T, Pirildar S. Sexual function in ankylosing spondylitis: a study of 65 men. $J$ Urol 2004; 171: 1598-1600.

11 Clapauch R, Braga DJC, Marinheiro LP, Buksman S, Schrank Y. Risk of late onset hypogonadism (andropause) in Brazilian men over 50 years of age with osteoporosis: usefulness of screening questionnaires. Arq Bras Endocrinol Metab 2008; 52: 1439-1447.

12 Heo OHJS, Kim H-M, Lee Y-G, Yoo SG, B. The effect of antitumor necrosis factor agent on sexual dysfunction in male patients 
with ankylosing spondylitis: a pilot study. Int J Impot Res 2009; 21: $372-375$

13 Le Pioufle N, Djafari M, Garcier JM, De Fraissinette B, Boyer L Thrombosis of the superficial dorsal vein of the penis (penile Mondor's phlebitis). The interest of Doppler examination. Presse Med 2003; 32: 1074-1076.
14 Chitaley K, Kupelian K, Subak L, Wessells H. Diabetes, obesity and erectile dysfunction: field overview and research priorities. J Urol 2009; 182: 45-50.

15 Silva CAA, Moraes AJP, Leal MM, et al. Aspects of reproductive health in men with idiopathic inflamamtory myopathy. A multicentre study. Braz J Rheumatol 2009; 49: 677-689. 


\title{
APÊNDICE 3
}

\begin{abstract}
Artigo "Morphofunctional penile alterations with severe sperm abnormalities in antiphospholipid syndrome associated with systemic lupus erythematosus"
\end{abstract}

\section{Enviado em 28 de setembro de 2011 para Revista Lupus}

\section{8-Sep-2011}

Dear Prof. Silva:

Your manuscript entitled "MORPHOFUNCTIONAL PENILE ALTERATIONS WITH SEVERE SPERM ABNORMALITIES IN ANTIPHOSPHOLIPID SYNDROME ASSOCIATED WITH SYSTEMIC LUPUS ERYTHEMATOSUS" has been successfully submitted online and is being considered for processing.

Your manuscript ID is LUP-11-404.

Please quote the above manuscript ID in all future correspondence. If there are any changes in your street address or e-mail address, please log in to Manuscript Central at http://mc.manuscriptcentral.com/lupus and edit your user information as appropriate.

You can also view the status of your manuscript at any time by checking your Author Center after logging in to http://mc.manuscriptcentral.com/lupus .

Thank you very much for submitting your manuscript to Lupus.

Kind regards.

Yours sincerely

Denzil Fletcher

Lupus Editorial Office 
CONCISE ARTICLE

MORPHOFUNCTIONAL PENILE ALTERATIONS WITH SEVERE SPERM ABNORMALITIES IN ANTIPHOSPHOLIPID SYNDROME ASSOCIATED WITH SYSTEMIC LUPUS ERYTHEMATOSUS

Carlos Nobre Rabelo-Júnior ${ }^{1}$, Eloisa Bonfá ${ }^{1}$, Jozélio F. Carvalho ${ }^{1}$, Marcello Cocuzza $^{2}$, Osmar Saito ${ }^{3}$, Carmita H. Abdo ${ }^{4}$, Clovis A. Silva ${ }^{1,5}$

Division of Rheumatology ${ }^{1}$, Department of Urology ${ }^{2}$, Department of Radiology ${ }^{3}$, Department of Psichiatry ${ }^{4}$, Paediatric Rheumatology Unit ${ }^{5}$, Faculdade de Medicina da Universidade de São Paulo, São Paulo - Brazil

Address correspondence and reprint requests to:

Clovis Artur Almeida Silva, MD, PhD

Disciplina de Reumatologia, Faculdade de Medicina da Universidade de São Paulo.

Av. Dr. Arnaldo 455, sala 3133, São Paulo, SP, Brazil. CEP: 01246-903

FAX: 55-11-3066-7490.

E-mail: clovis.silva@icr.usp.br 


\section{ABSTRACT}

Objective: To perform global gonadal and sexual function assessments in systemic lupus erythematosus related antiphospholipid syndrome (SLE-APS) patients.

Methods: A cross-sectional study was conducted in 10 SLE-APS male patients and 20 healthy controls. They were assessed by demographic data, clinical features, systematic urological examination, sexual function, testicular ultrasound, seminal parameters according to World Health Organization (WHO), seminal sperm antibodies and hormone profile including: follicle stimulating hormone $(\mathrm{FSH})$, luteinizing hormone (LH), morning total testosterone and thyroid hormones.

Results: The median of current age was similar in SLE-APS patients and controls ( 36.9 vs. 32.4 years, $p=0.310$ ), with a higher frequency of erectile dysfunction in the former group ( $30 \%$ vs. $0 \%, p=0.029)$. Further analysis revealed that the median penis circumference was significantly reduced in SLE-APS patients with erectile dysfunction compared to patients without this complication [8.17 (8-8.5) vs. $9.14(7-10.5) \mathrm{cm}, \mathrm{p}=0.0397]$. In addition, SLE-APS patients with previous arterial thrombosis had a significantly reduced median penis circumference compared to those without this complication [7.5 (7-8) vs. $9.18(8-10.5) \mathrm{cm}, \mathrm{p}=0.039]$. Comparing SLE-APS patients and controls, the former had a significant lower median of sperm concentration ( 41.1 vs. $120.06 \times 10^{6} / \mathrm{mL}, \mathrm{p}=0.003$ ), percentages of sperm motility ( 47.25 vs. $65.42 \%, p=0.047$ ), normal sperm forms evaluated by WHO guidelines (11 vs. $23.95 \%, p=0.002$ ) and Kruger criteria (2.65 vs. 
$7.65 \%, p=0.02$ ). The median of FSH levels was significantly higher in SLE-APS group (9.73 vs. $3.32 \mathrm{IU} / \mathrm{liter}, \mathrm{p}=0.025$ ). Regarding seminal analysis, the median of sperm concentration and total sperm count were significantly lower in SLE-APS patients treated with intravenous cyclophosphamide versus untreated with this drug $\left[6.87(0-23.5)\right.$ vs. $63.9(7.5-145) \times 10^{6} / \mathrm{mL}$, $\mathrm{p}=0.04 ; 16.12(0-55.5)$ vs. $226.25(8.5-471) \times 10^{6} / \mathrm{mL}, \mathrm{p}=0.035$, respectively].

Conclusions: We have identified that IVCYC underlies severe sperm alterations in SLE-APS and we also observed a novel association of reduced penile size with erectile dysfunction and previous arterial thrombosis in these patients.

Keywords: antiphospholipid syndrome, systemic lupus erythematosus, sperm, penile, fertility, antisperm antibodies.

\section{INTRODUCTION}

We identified severe sperm abnormalities associated with intravenous cyclophosphamide (IVCYC) use ${ }^{1,2}$ and reduced penile dimensions with no deleterious effect in erectile function in systemic lupus erythematosus (SLE) patients. ${ }^{3}$ In contrast, our group recently observed normal testicular function in primary antiphospholipid syndrome (PAPS) patients, in spite of morphofunctional penile abnormalities. Previous arterial thrombosis seemed to underlie this penile anthropometry alteration in PAPS. ${ }^{4}$ There is, however, no systematic study assessing the overall gonadal function in SLE-APS patients. 
Therefore, the aim of this study was to perform global testicular and sexual function assessments in male SLE-APS evaluating its possible association with clinical and laboratorial parameters.

\section{PATIENTS AND METHODS}

\section{SLE-APS patients and controls}

We screened initially 38 male patients with APS without a medical history of hydrocele, hypospadia, cryptorchidism, testicular infection, testicular cancer, orchitis, testicular vasculitis, ureteral impairment, previous history of any scrotal or inguinal surgery, diabetes mellitus and tobacco use. None of the participants had history of alcohol consumption or heavy occasional drinking before or at study entry. Of the 38 patients, 28 patients were excluded due to previous vasectomy $(n=3)$, refusal to collect sperm sample ( $n=9)$, PAPS $(n=12)$ and APS associated with others rheumatic diseases $(n=4)$ [polyarteritis nodosa $(n=2)$, rheumatoid arthritis $(n=1)$ and ankylosing spondylitis $(n=1)]$. Therefore, a cross-sectional study was conducted in 10 SLE-APS patients regularly followed at Antiphospholipid Outpatient Clinic of the Rheumatology Division of Hospital das Clínicas da Faculdade de Medicina da Universidade de São Paulo from May 2008 to February 2011. All patients fulfilled the Sapporo and American College of Rheumatology for $\mathrm{APS}^{5}$ and SLE diagnosis, ${ }^{6}$ respectively. The control group included 20 healthy subjects followed at the Pre-vasectomy Group of Urology Division of our University Hospital. All SLE-APS patients and controls were at 
Tanner stage $5 .^{7}$ The Local Ethics Committee approved this study and an informed consent was obtained from all participants

\section{GLOBAL REPRODUCTIVE HEALTH EVALUATION}

1. Demographic data and body mass index: Current age, age at spermarche (first ejaculation) and race were recorded in SLE-APS patients and controls, while age at disease onset and disease duration in SLE-APS patients. Body mass index (BMI) was defined by the formula: BMI $\left(\mathrm{Kg} / \mathrm{m}^{2}\right)$ weight in kilograms/height in meters.

2. Urologic evaluation and sexual function: A clinical assessment of the genitalia included evaluation of testicles, epididymis, vas deferens, scrotum and penis. These assessments were performed blinded to the results of the semen in SLE-APS patients and controls. Penis length was measured as linear distance along the dorsal side of penis extending from the pubopenile skin junction to the tip of the glands in the flaccid state, while penis circumference was measured at the middle of shaft. ${ }^{3,4}$ The evaluation of sexual function in patients and controls was acquired by the male sexual quotient, an self-administered questionnaire validated in Brazilian Portuguese. $^{8}$ 
3. Testicular Doppler Ultrasound: Ultrasound was performed blinded to the results of the semen in SLE-APS patients and controls. The largest measurement in each dimension was recorded and used to calculate the testicular volume according to the formula for an ellipsoid (length $\mathrm{X}$ width $\mathrm{X}$ thickness $X$ 0.52). The normal mean $\pm S D$ value in male post pubertal adolescents and adults is 7-23 $\mathrm{ml}^{1-4}$

4. Hormone evaluation:Hormone determinations performed at study entry in SLE-APS patients and controls, included: follicle-stimulating hormone (FSH), luteinizing hormone (LH), morning total testosterone, triiodothyronine (T3), tetraiodothyronine (T4), free tetraiodothyronine (free T4), and thyrotropin (TSH) detected by fluoroimmunoassay using DELFIA time-resolved fluoroimmunoassay kits (Wallac, Turku, Finland). Intra- and inter-assay coefficients of variation were limited to $3.5 \%$ and $2.1 \%$, respectively. The normal ranges were: FSH (1-10.5 IU/l), LH (1-8.4 IU/l), total morning testosterone (271-965 ng/dL), T3 (70-200 ng/dL), T4 (4.5-12 $\mu \mathrm{g} / \mathrm{dL})$, free T4 (0.7-1.5 ng/dl) and TSH (0.4-4.5 $\mu \mathrm{U} / \mathrm{mL})$.

5. Sperm evaluation: Sperm analysis was performed according to the guidelines of the World Health Organization $(\mathrm{WHO})^{9}$ by two expert medical technologists. All SLE-APS patients and controls collected two semen samples with interval of 15-30 days after 48-72 hours of sexual abstinence. The spermatozoa were analyzed by manual hand count as well as by a computer-assisted semen analysis system under 400X magnification, using 
an HTM-2030. Sperm morphology included evaluation of sperm head, neck, midpiece, and tail by WHO guidelines ${ }^{9}$ and Kruger strict criteria. ${ }^{10}$ Azoospermia was defined as no spermatozoa in the ejaculate and oligozoospermia as sperm concentration $<20$ million $/ \mathrm{mL}^{9}{ }^{9}$ The presence of antisperm antibodies was determined by direct Immunobead test using Immunobead $^{R}$ rabbit anti-human $\lg (\lg A, \lg G$, and $\lg M)$ kits (Irvine Scientific, Santa Ana, CA, USA) in all patients and controls. At least $50 \%$ of the motile spermatozoa ("a" + "b") must be coated with Immunobeads before the test results are considered to be clinically significant. A negative control should have a score of $<10 \%$ bead attachment, and a positive control should have a score of $>20 \%$ bead attachment. $^{9}$

6. Clinical and treatment evaluations: The following clinical parameters were evaluated in SLE-APS patients: venous thrombosis (documented deep vein thrombosis and/or pulmonary embolism), arterial thrombosis (clinically documented stroke, transient ischemic attacks or acute myocardial infarction), livedo reticularis and thrombocytopenia $\left(<100,000 / \mathrm{mm}^{3}\right.$ platelets, at least in two distinct occasions). SLE disease activity and cumulative damage at the time of study entry were measured in all patients, using the SLE Disease Activity Index (SLEDAI) ${ }^{11}$ and the Systemic Lupus International Collaborating Clinics/ACR Damage Index (SLICC/ACR-DI), respectively. ${ }^{12}$ Data concerning the therapy were evaluated. 
7. Serum immunologic analysis. Anticardiolipin antibodies were detected by a commercial kit (Enzyme Immunoassay Kit, BINDAZYME ${ }^{\mathrm{TM}}$, Birmingham, UK) in all APS patients. The cutoff values were: $<11 \mathrm{GPL} / \mathrm{MPL}$ $\mathrm{U} / \mathrm{mL}$ negative, $\geq 11$ and $<20 \mathrm{GPL} / \mathrm{MPL} \mathrm{U} / \mathrm{mL}$ indeterminate and $\geq 20$ GPL/MPL U/mL positive. ${ }^{13}$ Lupus anticoagulant (LAC) was detected according to international guidelines. ${ }^{14}$ Serum IgG and IgM anti-beta-2-glycoprotein I were detected by Enzyme-Linked Immunoabsorbent Assay (ELISA) technique (ORG 521 Anti-beta-2-Glycoprotein I lgG/lgM Mainz, Germany) with cutoff values of 8 $\mathrm{U} / \mathrm{mL}$ for IgM and for IgG with intra-assay variation: $2.1-5.0 \%$; inter-assay variation: $2.6-7.95$ to $\lg G$ and intra-assay variation: $2.1-3.8 \%$; inter-assay variation: $4.1-6.3$ to $\lg M$.

8. Statistical analysis: Data were compared by $t$-test or Mann-Whitney's test if numerical data presented normal or abnormal distribution, respectively, to evaluate differences between SLE-APS patients and controls, and according to previous arterial thrombosis and erectile dysfunction in SLE-APS patients. For categorical variables, differences were assessed by Fisher's exact test. $P$ values less than 0.05 were considered significant.

\section{RESULTS}

\section{SLE-APS patients versus controls}

The demographic data, BMI, penile anthropometry, testicular volume by ultrasound, sperm analysis, antisperm antibodies and hormone evaluation 
in SLE-APS patients and controls are shown in Table 1. The median of current age was similar in both groups [36.9 (21-57) vs. 32.4 (18-54) years, $\mathrm{p}=0.310]$. In contrast, the median age of spermarche and BMI were significantly higher in SLE-APS patients versus controls [13.9 (12-16) vs. $12.85(11-15)$ years, $\mathrm{p}=0.016 ; 26.9$ (22-35.2) vs. 22.2 (18-27), $\mathrm{p}=0.003$; respectively] (Table 1).

The frequency of erectile dysfunction was significantly higher in SLE-APS patients compared to controls ( $30 \%$ vs. $0 \%, \mathrm{p}=0.029)$. The median right testicular volume by ultrasound was significantly lower in SLE-APS patients [10.38 (3.9-16.7) vs. $13.4(8.5-20.6) \mathrm{ml}, \mathrm{p}=0.03]$. No differences were observed in penis anthropometry and left testicular volume in both groups (Table 1).

The median of sperm concentration and sperm motility were significantly lower in SLE-APS patients compared to controls [41.1 (0-145) vs. $120.06(34.5-329) \times 10^{6} / \mathrm{mL}, \mathrm{p}=0.003 ; 47.25(0-87.5)$ vs. $65.42(43-82) \%$, $\mathrm{p}=0.047$, respectively]. Normal sperm forms evaluated by $\mathrm{WHO}$ guidelines and Kruger strict criteria were significantly lower in SLE-APS patients [11 (0-27) vs. $23.95(10-45) \%, p=0.002 ; 2.65$ (0-8) vs. $7.65(3-18) \%, p=0.02$, respectively]. The frequency of oligo/azoopermia was significantly higher in SLE-APS patients ( $40 \%$ vs. $0 \%, p=0.007$ ). The median of FSH levels and frequencies of elevated FSH were significantly higher in SLE-APS group [9.73 (2.4-25) vs. $3.32(1-5.9)$ IU/liter, $p=0.025 ; 40 \%$ vs. $0 \%, p=0.007$; respectively] (Table 1). All SLE-APS patients and controls had normal thyroid hormones. 


\section{SLE-APS patients}

The median penis circumference was significantly lower in SLE-APS patients with $(n=3)$ erectile dysfunction versus without $(n=7)$ this alteration [8.17 (8-8.5) vs. 9.14 (7-10.5) cm, $p=0.0397]$. No differences were evidenced in the median penis length in both groups [10.83 (9-12.5) vs. 10.14 (7.5-13) $\mathrm{cm}, \mathrm{p}=0.615]$. SLE-APS patients with previous arterial thrombosis $(\mathrm{n}=2)$ had a significantly reduced median penis circumference than those without arterial events $(n=8)[7.5(7-8)$ vs. $9.18(8-10.5) \mathrm{cm}, \mathrm{p}=0.039]$, whereas the median of length in both groups was comparable [8.25 (7.5-9) vs. 10.87 (8.5-13) $\mathrm{cm}, \mathrm{p}=0.08]$. Testicular volumes, sperm analysis, antisperm antibodies, hormone profile, thrombocytopenia, SLEDAI, SLICC/ACR-DI, IgM anticardiolipin, IgG anticardiolipin, IgM anti-beta2-glicoprotein I, IgG anti-beta2-glicoprotein I and lupus anticoagulant were alike in patients treated with IVCYC and those never under this treatment $(p>0.05)$. None of the SLE-APS patients reported history of penile edema or pain.

IVCYC was used for lupus nephritis treatment in four patients. The median duration of time from last dose of IVCYC to study entry was 6 years (2-9). The median of disease duration was significantly higher in those treated with $(n=4)$ IVCYC compared never under this drug $(n=6)$ [9.92 $(5-13)$ vs. $3.38(0.3-7)$ years, $p=0.028]$. The median of sperm concentration and total sperm count were significantly lower in SLE-APS patients treated with IVCYC versus untreated with this drug $[6.87(0-23.5)$ vs. $63.9(7.5-145) \mathrm{x}$ $10^{6} / \mathrm{mL}, \mathrm{p}=0.04 ; 16.12(0-55.5)$ vs. $226.25(8.5-471) \times 10^{6} / \mathrm{mL}, \mathrm{p}=0.035$, respectively] while no difference was observed for the other sperm 
parameters $(p>0.05)$. Penis anthropometry, testicular volumes, antisperm antibodies, hormone profile, SLEDAI, SLICC/ACR-DI were alike in patients treated with IVCYC and those never under this treatment $(p>0.05)$.

\section{DISCUSSION}

Herein we have demonstrated that IVCYC underlies severe sperm alterations in SLE-APS patients and we also observed for the first time an association of reduced penile size with erectile dysfunction and previous arterial thrombosis in these patients.

The advantage of the present study was the use of a global protocol and the inclusion of only post-pubertal subjects, assuring a more homogeneous group regarding gonadal and sexual evaluation. The systematic penile, gonadal and sexual assessments were carried out using established criteria for penis anthropometry, ${ }^{3,4}$ sperm and antisperm antibodies, ${ }^{1,2,9}$ and sexual function. ${ }^{8}$ The rigorous exclusion criteria of SLE-APS patients and controls without a medical history of genital diseases and comorbidities is relevant since these alterations may affect gonadal evaluation. ${ }^{15}$ The low number of patients and the cross sectional design are limitations of this study.

The penile development is influenced by race, hypothalamic-pituitarytesticular axis dysfunction and chronic diseases, as described in our SLE without APS and in PAPS patients. ${ }^{3,4}$ Of note, SLE-APS patients evaluated herein with previous arterial events had reduced circumference penile size, 
suggesting the possibility that chronic subclinical endothelial dysfunction involving corpora cavernosa or penis arteries may result in atrophy and sexual alteration. ${ }^{16}$ These findings were also observed in our PAPS patients ${ }^{4}$ and we are currently carrying out penis pharmacologic ultrasound in lupus patients with APS to evaluate the reduced penis blood flow and intimal proliferation of penile vessels. Interestingly, none of the patients reported history of penile edema or pain, as also observed in PAPS patients. ${ }^{4}$

Erectile dysfunction occurred particularly in SLE-APS patients with reduced penile circumference, as also evidenced in our previous study evaluating PAPS patients. ${ }^{4}$ This sexual dysfunction is characterized by the inability of man to achieve and maintain an erection sufficient for satisfactory sexual performance. ${ }^{8}$ Sexual impotence of our SLE-APS patients may be linked to local subclinical endothelial cells dysfunction, and may cause psychological problems with a consequent reduction of health-related quality of life. ${ }^{4}$ Further studies, including the evaluation of efficacy and safety of phosphodiesterase type 5 (PDE-5) inhibitors in this population of autoimmune thrombosis, will be necessary.

Additionally, in our lupus patients with APS, we have confirmed our previous observation of sperm abnormalities, reduced of testicular volume and gonadal hormone alterations in SLE without this thrombophilic disorder. ${ }^{1-3}$ Importantly, the use of cyclophosphamide seemed to contribute to severe semen alterations in our SLE-APS patients leading a persistent or long-lasting damage to primordial sperm cells, as also observed in our male SLE without this condition. ${ }^{1}$ This study emphasizes the importance of sperm 
cryopreservation for future assisted reproductive techniques before alkylating agents use..$^{15,17}$

Of note, no clear etiology for SLE-APS delayed spermarche was identified herein. The possible influence of disease or drug was suggested in our previous study in female juvenile SLE ${ }^{18-20}$ and juvenile dermatomyositis ${ }^{21}$ patients with late occurrence of menarche in which disease occurred before first menstruation compared with normal Brazilian adolescents. This was not, however, the case in male SLE-APS since all of our patients had disease onset after spermarche.

In conclusion, we have identified that IVCYC is the major factor for severe and potentially permanent damage to the tests in SLE-APS patients. We also observed for the first time an association of reduced penile size with erectile dysfunction and previous arterial thrombosis in these patients.

\section{ACKNOWLEDGMENTS}

This study was supported by Fundação de Amparo à Pesquisa do Estado de São Paulo - FAPESP (grants 2004/07832-2 and 2005/56482-7 to CAS) and Conselho Nacional de Desenvolvimento Científico e Tecnológico CNPQ (grants $301411 / 2009-3$ to EB, 3300665/2009-1 to JFC and 300248/2008-3 to CAS) and Federico Foundation Grants to JFC, EB and CAS. Our gratitude to Maribê Salan Marcos and Rosa Casemiro for technical support, and Francisco Erivelton Aragão for the statistical analysis. 


\section{REFERENCES}

1. Soares PM, Borba EF, Bonfa E, Hallak J, Corrêa AL, Silva CA. Gonad evaluation in male systemic lupus erythematosus. Arthritis Rheum 2007; 56: 2352-2361.

2. Suehiro RM, Borba EF, Bonfa E, et al. Testicular Sertoli cell function in male systemic lupus erythematosus. Rheumatology (Oxford) 2008; 47: 1692-1697.

3. Vecchi A, Borba E, Bonfá E, et al. Penile anthropometry in systemic lupus erythematosus patients. Lupus 2011; 20: 512-518.

4. Rabelo-Júnior CN, Carvalho JF, Gallinaro AL. Primary antiphospholipid syndrome: morphofunctional penile abnormalities with normal sperm analysis. Lupus 2011 (published online).

5. Wilson WA, Gharavi AE, Koike $\mathrm{T}$, et al. International consensus statement on preliminary classification criteria for definite antiphospholipid syndrome: report of an international workshop. Arthritis Rheum 1999; 42: 1309-1311.

6. Hochberg MC. Updating the American College of Rheumatology revised criteria for the classification of systemic lupus erythematosus. Arthritis Rheum 1997; 40: 1725.

7. Tanner JM. Growth at adolescence. 2nd edition. Oxford: Blackwell Scientific Publications, 1962.

8. Abdo $\mathrm{CH}$. The male sexual quotient: a brief, self-administered questionnaire to assess male sexual satisfaction. J Sex Med 2007; 4: 382-389. 
9. World Health Organization (WHO). Laboratory manual for the examination of human semen and sperm-cervical mucus interaction. 4th ed. New York: Cambridge University Press; 1999:1-128.

10. Kruger TF, Acosta AA, Simmons KF, Swanson RJ, Matta JF, Oehninger S. Predictive value of abnormal sperm morphology in vitro fertilization. Fertil Steril 1988; 49: 112-117.

11. Bombardier C, Gladman DD, Urowitz MB, Karon D, Chang $\mathrm{CH}$ and The Committee on Prognosis Studies in SLE. Derivation of the SLEDAI: a disease activity index for lupus patients. Arthritis Rheum 1992; 35: 630640.

12. Gladman D, Ginzler E, Goldsmith C, et al. The development and initial validation of the Systemic Lupus International Collaborating Clinics/American College of Rheumatology Damage Index for systemic lupus erythematosus. Arthritis Rheum 1996; 39: 363-369.

13. Haris EN, Pierangeli S, Birch D. Cardiolipin Wet Workshop report. Am J Clin Path 1994, 101: 616-624.

14. Wisloff F, Jacobsen EM, Liestol S. Laboratory diagnosis of the antiphospholipid syndrome. Thromb Res 2002; 108: 263-271.

15. Silva CA, Bonfa E, Ostensen M. Maintenance of fertility in patients with rheumatic diseases needing anti-inflammatory and immunosuppressive drugs. Arthritis Care Res (Hoboken) 2010; 62: 1682-1690.

16. El-Sakka AI, Yassin AA. Amelioration of penile fibrosis: myth or reality. J Androl 2010; 31: 324-335. 
17. Silva CA, Brunner HI. Gonadal functioning and preservation of reproductive fitness with juvenile systemic lupus erythematosus. Lupus 2007; 16: 593-599.

18. Silva CA, Leal MM, Leone C, Simone VP, Takiuti AD, Saito Ml, et al. Gonadal function in adolescents and young female with systemic lupus erythematosus. Lupus 2002; 11: 419-425.

19. Febronio MV, Pereira RM, Bonfa E, Takiuti AD, Pereyra EA, Silva CA. Inflammatory cervicovaginal cytology is associated with disease activity in juvenile systemic lupus erythematosus. Lupus 2007; 16: 430-543.

20. Medeiros PB, Febrônio MV, Bonfá E, Borba EF, Takiuti AD, Silva CA. Menstrual and hormonal alterations in juvenile systemic lupus erythematosus. Lupus 2009; 18: 38-43.

21. Aikawa NE, Sallum AM, Leal MM, Bonfá E, Pereira RM, Silva CA. Menstrual and hormonal alterations in juvenile dermatomyositis. Clin Exp Rheumatol 2010; 28: 571-575. 
Table 1 - Demographic data and body mass index (BMI), penis anthropometry, testicular volume by ultrasound, sperm analysis, anti-sperm antibodies and hormone evaluation in systemic lupus erythematosus related antiphospholipid syndrome (SLE-APS) patients and healthy controls.

\begin{tabular}{|c|c|c|c|}
\hline Variables & $\begin{array}{c}\text { SLE-APS } \\
(n=10)\end{array}$ & $\begin{array}{c}\text { Controls } \\
(n=20)\end{array}$ & $\mathbf{P}$ \\
\hline \multicolumn{4}{|l|}{ Demographic data and BMI } \\
\hline Current age, years & $36.9(21-57)$ & $32.4(18-54)$ & 0.310 \\
\hline Age at disease onset, years & $32.20(14-57)$ & & \\
\hline Disease duration, years & $5.73(0.3-13)$ & - & - \\
\hline Age at spermarche, years & $13.9(12-16)$ & $12.85(11-15)$ & 0.016 \\
\hline Caucasian race & $4(40)$ & $7(33)$ & 1.0 \\
\hline $\mathrm{BMI}, \mathrm{Kg} / \mathrm{m}^{2}$ & $26.9(22-35.2)$ & $22.2(18-27)$ & 0.003 \\
\hline \multicolumn{4}{|l|}{$\begin{array}{l}\text { Penis anthropometry and erectile } \\
\text { dysfunction }\end{array}$} \\
\hline Length, cm & $10.35(7.5-13)$ & $10.02(8-13)$ & 0.575 \\
\hline Circumference, $\mathrm{cm}$ & $8.85(7-10.5)$ & $9.42(7-11)$ & 0.18 \\
\hline Erectile dysfunction & $3(30)$ & 0 & 0.029 \\
\hline \multicolumn{4}{|l|}{ Testicular volume } \\
\hline Right, mL & $10.38(3.9-16.7)$ & $13.41(8.5-20.6)$ & 0.03 \\
\hline Left, mL & $11.04(7.2-17.2)$ & $12.85(6-21.2)$ & 0.07 \\
\hline \multicolumn{4}{|l|}{ Sperm analysis } \\
\hline Sperm volume, $\mathrm{ml}$ & $2.95 \pm 1.16$ & $1.66 \pm 1.28$ & 0.35 \\
\hline Sperm concentration, $x 106 / \mathrm{ml}$ & $41.1(0-145)$ & $120.06(34.5-329)$ & 0.003 \\
\hline Oligo/azoospermia & $4(40)$ & 0 & 0.007 \\
\hline Total sperm count, $\times 10^{6}$ & $142.2(0-471)$ & $300.5(41.3-1176)$ & 0.06 \\
\hline Sperm motility, \% & $47.25(0-87.5)$ & $65.42(43-82)$ & 0.047 \\
\hline Normal sperm forms byWHO guidelines, $\%$ & $11(0-27)$ & $23.95(10-45)$ & 0.002 \\
\hline Normal sperm forms by Kruger, $\%$ & $2.65(0-8)$ & $7.65(3-18)$ & 0.02 \\
\hline Antisperm antibodies, $\%$ & $17.2(9-23)$ & $16.9(0-32)$ & 0.92 \\
\hline \multicolumn{4}{|l|}{ Hormone evaluation } \\
\hline FSH, IU/liter & $9.73(2.4-25)$ & $3.32(1-5.9)$ & 0.025 \\
\hline Elevated levels & $4(40)$ & 0 & 0.007 \\
\hline LH, IU/liter & $6.87(1.6-21.7)$ & $3.49(1.8-5.8)$ & 0.074 \\
\hline Elevated levels & $2(20)$ & 0 & 0.103 \\
\hline Morning total testosterone, ng/dl & $434.3(91-891)$ & $552.5(230-1078)$ & 0.09 \\
\hline Lower levels & 0 & $1(5)$ & 1.0 \\
\hline
\end{tabular}

Values expressed in mean \pm SD, median (range) or $n(\%), n$ - number of patients and controls, WHO - World Health Organization, FSH - follicle-stimulating hormone (reference values 1-10.5 IU/liter), LH - luteinizing hormone (reference values 1-8.4) IU/liter, morning total testosterone (271-965 ng/dl). 